\title{
Sex-dependent calcium hyperactivity due to lysosomal-related dysfunction in astrocytes from APOE4 versus APOE3 gene targeted replacement mice
}

Raquel Larramona-Arcas ${ }^{1}$, Candela González-Arias², Gertrudis Perea², Antonia Gutiérrez ${ }^{3,4}$, Javier Vitorica ${ }^{4,5}$, Tamara García-Barrera ${ }^{6}$, José Luis Gómez-Ariza ${ }^{6}$, Raquel Pascua-Maestro ${ }^{7}$, María Dolores Ganfornina”, Eleanna Kara ${ }^{8,9}$, Eloise Hudry ${ }^{8}$, Marta Martinez-Vicente ${ }^{4,10}$, Miquel Vila ${ }^{1,4,10,11}$, Elena Galea ${ }^{1,11 \dagger}$ and Roser Masgrau ${ }^{1 *+}$ (D)

\footnotetext{
Abstract

Background: The apolipoprotein E (APOE) gene exists in three isoforms in humans: APOE2, APOE3 and APOE4. APOE4 causes structural and functional alterations in normal brains, and is the strongest genetic risk factor of the sporadic form of Alzheimer's disease (LOAD). Research on APOE4 has mainly focused on the neuronal damage caused by defective cholesterol transport and exacerbated amyloid- $\beta$ and Tau pathology. The impact of APOE4 on non-neuronal cell functions has been overlooked. Astrocytes, the main producers of ApoE in the healthy brain, are building blocks of neural circuits, and $\mathrm{Ca}^{2+}$ signaling is the basis of their excitability. Because APOE4 modifies membrane-lipid composition, and lipids regulate $\mathrm{Ca}^{2+}$ channels, we determined whether APOE4 dysregulates $\mathrm{Ca}^{2+}$ signaling in astrocytes.

Methods: $\mathrm{Ca}^{2+}$ signals were recorded in astrocytes in hippocampal slices from APOE3 and APOE4 gene targeted replacement male and female mice using $\mathrm{Ca}^{2+}$ imaging. Mechanistic analyses were performed in immortalized astrocytes. $\mathrm{Ca}^{2+}$ fluxes were examined with pharmacological tools and $\mathrm{Ca}^{2+}$ probes. APOE3 and APOE4 expression was manipulated with GFP-APOE vectors and APOE siRNA. Lipidomics of lysosomal and whole-membranes were also performed.

(Continued on next page)
}

\footnotetext{
* Correspondence: roser.masgrau@uab.cat

†Elena Galea and Roser Masgrau contributed equally to this work.

'Unitat de Bioquímica de Medicina, Departament de Bioquímica i Biologia Molecular, and, Institut de Neurociències (INc), Facultat de Medicina,

Universitat Autònoma de Barcelona, 08193 Cerdanyola del Vallès, Barcelona, Catalonia, Spain

Full list of author information is available at the end of the article
}

(C) The Author(s). 2020 Open Access This article is licensed under a Creative Commons Attribution 4.0 International License, which permits use, sharing, adaptation, distribution and reproduction in any medium or format, as long as you give appropriate credit to the original author(s) and the source, provide a link to the Creative Commons licence, and indicate if changes were made. The images or other third party material in this article are included in the article's Creative Commons licence, unless indicated otherwise in a credit line to the material. If material is not included in the article's Creative Commons licence and your intended use is not permitted by statutory regulation or exceeds the permitted use, you will need to obtain permission directly from the copyright holder. To view a copy of this licence, visit http://creativecommons.org/licenses/by/4.0/ The Creative Commons Public Domain Dedication waiver (http://creativecommons.org/publicdomain/zero/1.0/) applies to the data made available in this article, unless otherwise stated in a credit line to the data. 
(Continued from previous page)

Results: We found potentiation of ATP-elicited $\mathrm{Ca}^{2+}$ responses in APOE4 versus APOE3 astrocytes in male, but not female, mice. The immortalized astrocytes modeled the male response, and showed that Ca ${ }^{2+}$ hyperactivity associated with APOE4 is caused by dysregulation of $\mathrm{Ca}^{2+}$ handling in lysosomal-enriched acidic stores, and is reversed by the expression of APOE3, but not of APOE4, pointing to loss of function due to APOE4 malfunction. Moreover, immortalized APOE4 astrocytes are refractory to control of $\mathrm{Ca}^{2+}$ fluxes by extracellular lipids, and present distinct lipid composition in lysosomal and plasma membranes.

Conclusions: Immortalized APOE4 versus APOE3 astrocytes present: increased $\mathrm{Ca}^{2+}$ excitability due to lysosome dysregulation, altered membrane lipidomes and intracellular cholesterol distribution, and impaired modulation of $\mathrm{Ca}^{2+}$ responses upon changes in extracellular lipids. Ca ${ }^{2+}$ hyperactivity associated with APOE4 is found in astrocytes from male, but not female, targeted replacement mice. The study suggests that, independently of $A \beta$ and Tau pathologies, altered astrocyte excitability might contribute to neural-circuit hyperactivity depending on APOE allele, sex and lipids, and supports lysosome-targeted therapies to rescue APOE4 phenotypes in LOAD.

Keywords: APOE4, Astrocytes, Calcium signaling, Sex, Lysosome, Purinergic receptors, Lipidome

\section{Background}

Apolipoprotein $\mathrm{E}$ is a component of lipoproteins involved in extracellular lipid transport and cholesterol fluxes throughout the body, including the brain [1]. In humans, $A P O E$ exists in three isoforms: $A P O E 2,3$-the most common allele-and 4. Although the three isoforms differ only in the amino acids in positions 112 and 158 at the $\mathrm{N}$-terminal domain of the protein [2], this minimal difference results in a structural change in the $A P O E 4$ isoform that profoundly compromises its function [3], as shown by a wealth of studies in mice and humans that document the impact of $A P O E$ genotype on the structure and function of the healthy brain. Thus, in humans, APOE4 is associated with reduced memory retention [4], altered neural activity and brain connectivity [5], reduced grid-cell like representations [6], reduced dendritic spine density [7], and hypometabolism measured with fluorodeoxyglucose-based PET [8]. Furthermore, APOE4 knock-in mice present alterations of behavior, olfactory memory and neurotransmission, as well as decreased dendritic arborization and metabolic alterations [9-13], as compared to APOE3 knock-in mice. Not only is normal brain function compromised by $A P O E 4$, but $A P O E 4$ is also the strongest genetic risk factor in late-onset Alzheimer's disease (LOAD) [14], the principal cause of age-related dementia, affecting millions of people around the world [15]. A complex interaction exists among sex, age and APOE4 load. Thus, according to a meta-analysis, heterozygous APOE3/ $A P O E 4$ women present increased risk of LOAD between the ages of 65 and 75 years, and increased risk of mild cognitive impairment (MCI) between the ages of 55 and 70, as compared to men [16]. Homozygous APOE4 subjects show increased risk compared to $A P O E 3 / A P O E 4$ heterologous individuals [16-18], with men being at greater risk as reviewed by Riedel and colleagues [17] but not according to other authors [18]. In addition, detrimental actions of $A P O E 4$ have been reported in other neurodegenerative disorders such as frontotemporal dementia [19], cerebrovascular disease [20] and traumatic brain injury [21].

The mechanisms whereby APOE4 is pathological in normal and diseased brain are not totally clarified [15]. An outstanding question is whether APOE4 affects the function of brain cells other than neurons. Although microglia and neurons secrete ApoE in pathological conditions, as described in mouse neurons injured with kainic acid [22], and in human LOAD brains, where microglia produces and deposits ApoE in senile plaques [23] and appears to mediate Tau pathology [24], it is often overlooked that $A P O E$ is mainly synthesized, secreted, and lipidated by astrocytes in physiological and pathological conditions [3]. Astrocytes can also take up lipoproteins, as they express $A P O E$ receptors such as the LRP1 receptor [25].

Astrocytes are building blocks of neural circuits, where they modulate neuronal activity [26]. Apart from the impact of APOE4 on synaptogenesis [27] and synaptic transmission [28] by lowering the delivery of cholesterol from astrocytes to neurons, the question of whether APOE4 compromises the global control of astrocytes over neuronal activities has not been examined. Among phenomena modulated by astrocytes there are, to cite a few, long-term potentiation (LTP), memory consolidation, and circadian rhythms [29-32]. Central to astrocyte-to-neuron communication is $\mathrm{Ca}^{2+}$ signaling in astrocytes. Thus, although astrocytes are considered non-excitable cells in terms of action potentials, they respond by way of $\mathrm{Ca}^{2+}$ signals to neurotransmitters. In turn, such $\mathrm{Ca}^{2+}$ responses promote the release of several molecules called gliotransmitters, such as ATP, glutamate, D-serine or GABA $[29,30,32-34] . \mathrm{Ca}^{2+}$ signaling is 
thus considered the basis of astrocyte excitability, which is exquisitely precise owing to unique spatiotemporal $\mathrm{Ca}^{2+}$ features resulting from the combination of $\mathrm{Ca}^{2+}$ signaling pathways orchestrated by different second messengers, and intracellular organelles [35]. Pathways include inositol 1,4,5-triphosphate (IP3)-mediated $\mathrm{Ca}^{2+}$ release from the endoplasmic reticulum (ER) [36], and nicotinic acid adenine dinucleotide phosphate (NAADP)-elicited mobilization from acidic organelles, a heterogeneous population of vesicles highly enriched in lysosomes [37]. Extracellular $\mathrm{Ca}^{2+}$ entry and mitochondrial $\mathrm{Ca}^{2+}$ uptake can further shape cytosolic $\mathrm{Ca}^{2+}$ increases $[37,38]$. Of note, dysregulation of $\mathrm{Ca}^{2+}$ signaling in astrocytes has been reported in animal models of LOAD [39]. However, $\mathrm{Ca}^{2+}$ signaling has never been studied in astrocytes in the context of APOE4.

$A P O E$ genotype confers distinct composition to lipid membranes [40], and it is well established that lipid composition (e.g., contents of cholesterol and phospholipids) affects the function of membrane-associated enzymes, receptors, and channels [41]. On the basis of this evidence, we posited that $A P O E 4$ dysregulates $\mathrm{Ca}^{2+}$ excitability in astrocytes by modifying membrane lipid composition. To test this hypothesis, we studied ex vivo $\mathrm{Ca}^{2+}$ signaling in hippocampal astrocytes of female and male mice with human APOE3 and APOE4 gene targeted replacement of the endogenous mouse $A P O E$ $[42,43]$. We found that $\mathrm{Ca}^{2+}$ responses induced by the stimulation of purinergic receptors were upregulated in $A P O E 4$ versus (vs) $A P O E 3$ astrocytes in male, but not in female mice. Next, we clarified the underlying mechanisms in cultured immortalized astrocytes expressing human APOE3 and APOE4 [44]. The cells reproduced the ex vivo model of male mice, as $\mathrm{Ca}^{2+}$ responses were increased in immortalized APOE4 cells as compared to APOE 3 cells. Cultured APOE4 astrocytes released more $\mathrm{Ca}^{2+}$ from their acidic stores upon purinergic stimulation. Manipulation of APOE4 and APOE3 expression revealed that it is the allele, not the reduced synthesis, that caused altered $\mathrm{Ca}^{2+}$ signaling in immortalized APOE4 astrocytes. Finally, we demonstrated that APOE4 astrocytes have distinct lipidome and were refractory to control $\mathrm{Ca}^{2+}$ fluxes by extracellular lipids. Taken together, the data suggest that the $A P O E$ genotype modulates $\mathrm{Ca}^{2+}$ fluxes in astrocytes in a lipid, lysosome and sexdependent manner. Future research will clarify whether dysregulation of astrocyte excitability contributes to the increased risk of developing LOAD and other brain pathologies in APOE4 carriers.

\section{Materials and methods}

\section{Animal model}

Nine- to 12-week-old male and female $A P O E 3$ and APOE4 transgenic mice homozygous for the human
$A P O E 3$ or $A P O E 4$ gene replacing the endogenous mouse $A P O E$ gene were purchased from Taconic (USA) [42, 43]. All experimental procedures were performed according to the animal research regulations (RD53/2013 and 2010/63/UE) of Spain and the European Union, and with the approval of the Committees of Animal Research from the Institutional Animal Ethics Committee of CSIC. Animals were housed in standard laboratory cages with ad libitum access to food and water, under a 12:12 $\mathrm{h}$ dark-light cycle in temperature controlled rooms.

\section{Cell culture}

$A P O E 3$ and $A P O E 4$ immortalized astrocytes were a gift from Dr. Holtzman (Washington University) [44]. Immortalized astrocytes were routinely grown at $37^{\circ} \mathrm{C}$ in $5 \% \mathrm{CO}_{2}$ humidified atmosphere air in advanced DMEM medium supplemented with $1 \mathrm{mM}$ of $\mathrm{Na}^{+}$pyruvate, $10 \%$ fetal bovine serum (FBS), $100 \mathrm{U} / \mathrm{mL}$ of penicillin, $100 \mu \mathrm{g} / \mathrm{mL}$ of streptomycin, and $0.2 \mathrm{mg} / \mathrm{ml}$ of geneticine. Cell passages were performed with trypsin once per week up to passage 10 .

\section{$\mathrm{Ca}^{2+}$ imaging in astrocytes ex vivo in brain slices}

Animals were sacrificed; the brain was rapidly removed and placed in ice-cold modified artificial cerebrospinal fluid medium (ACSF). To reduce swelling and damage in superficial layers, N-methyl-D-glucamine (NMDG)ACSF was used during brain sectioning, NMDG being a substitute for sodium ions in a wide range of adult ages and applications [45]. NMDG-ACSF contained [in $\mathrm{mM}$ ]: NMDG 93, KCl 2.5, $\mathrm{NaH}_{2} \mathrm{PO}_{4} 1.2, \mathrm{NaHCO}_{3} 30$, HEPES $20, \mathrm{MgSO}_{4} 10, \mathrm{CaCl}_{2}$ 0.5, glucose 25 , sodium ascorbate 5 , thiourea 2 , sodium pyruvate 3 , gassed with $95 \% \mathrm{O}_{2} /$ $5 \% \mathrm{CO}_{2}$ (pH 7.3-7.4). Hippocampal slices $(350 \mu \mathrm{m})$ obtained with a vibratome (Leica Vibratome VT1200S, Germany) were incubated in NMDG-ACSF for $10 \mathrm{~min}$ at $34^{\circ} \mathrm{C}$, and then equilibrated for more than $1 \mathrm{~h}$ at room temperature $\left(22-24^{\circ} \mathrm{C}\right)$ prior cell loading with fluorochromes in ACSF containing [in $\mathrm{mM}$ ]: $\mathrm{NaCl} 124$, $\mathrm{KCl} 2.69, \mathrm{KH}_{2} \mathrm{PO}_{4} 1.25, \mathrm{MgSO}_{4} 2, \mathrm{NaHCO}_{3} 26, \mathrm{CaCl}_{2} 2$, and glucose 10 , gassed with $95 \% \mathrm{O}_{2} / 5 \% \mathrm{CO}_{2}(\mathrm{pH} 7.3-$ 7.4). Slices were loaded with sulforhodamine 101 (SR101, $1 \mu \mathrm{M}$ ) for $20 \mathrm{~min}$ at $34^{\circ} \mathrm{C}$ for astrocyte labeling [46-48], and washed in ACSF for $10 \mathrm{~min}$ at $34^{\circ} \mathrm{C}$. After SR101 labeling, slices were loaded with $2 \mathrm{mM}$ of fluo-4/ AM for $20-30 \mathrm{~min}$ at room temperature. After washing fluo-4/AM overloading in ACSF, slices were kept in ACSF medium supplemented with 10\% FBS at the stage of a Nikon Eclipse FN1 microscope coupled to a CCD camera (ORCA- $\mathrm{R}^{2}$, Hamamatsu, Japan). Cells were illuminated for $100-200 \mathrm{~ms}$ at $490 \mathrm{~nm}$ using LED system (CoolLED pE-100), and images from stratum radiatum astrocytes were acquired every $1 \mathrm{~s}$. The LED system and the camera were controlled and synchronized by the 
NIS-Elements software (Nikon, Japan) that was also used for epifluorescence measurements. Astrocyte $\mathrm{Ca}^{2+}$ levels were recorded from the astrocyte cell body, and $\mathrm{Ca}^{2+}$ variations were quantified as changes in the fluorescence signal $(\mathrm{F})$ over the baseline $\left(\mathrm{F}_{0}\right)\left(\left(\mathrm{F}-\mathrm{F}_{0}\right) / \mathrm{F}_{0}\right)$. Two protocols of $\mathrm{Ca}^{2+}$ monitoring were used. Firstly, spontaneous events were studied by recording $\mathrm{Ca}^{2+}$ events for $120 \mathrm{~s}$. Secondly, ATP-induced responses were studied by recording $\mathrm{Ca}^{2+}$ baseline for $30 \mathrm{~s}$, followed by local application of ATP $(1 \mathrm{mM} ; 5 \mathrm{~s})$ to activate purinergic receptors for $30 \mathrm{~s}$, and post ATP period for $60 \mathrm{~s}$. Local application of ATP was delivered by pressure pulses through a micropipette (Picospritzer II, Parker Hannifin, Mayfield Heights, OH, USA) in the presence of tetrodotoxin (TTX, $1 \mu \mathrm{M}$ ). Matlab software (MATLAB R2016; Mathworks Natick) custom-written plugin was used for computation of fluorescence values of each region of interest (ROI).

\section{$\mathrm{Ca}^{2+}$ imaging in astrocytes in vitro in immortalized astrocytes}

Intracellular $\mathrm{Ca}^{2+}$ measurement was performed using $2 \mu \mathrm{M}$ of fura-2/AM, a ratiometric fluorescence indicator whose fluorescence ratio $\left(\mathrm{R}_{340 / 380}\right)$ is proportional to $\mathrm{Ca}^{2+}$ concentration. Imaging of $\mathrm{Ca}^{2+}$ signaling in organelles was performed using genetically encoded $\mathrm{Ca}^{2+}$ indicators (GECI). The plasmids for endoplasmic reticulum (pCMV G-CEPIA1er) and mitochondrial (pCMV CEPIA3mt) were a gift from Masamitsu Iono [49]. Fluorescence was recorded using a TE-2000 U Nikon epifluorescence microscope keeping the cells at $37^{\circ} \mathrm{C}$. Cells were excited with a monochomator (Cairns, UK) and the emitted fluorescence was collected every $2 \mathrm{~s}$ by the high sensitivity CCD EG-ORCA camera (Hamamatsu Photonics, Japan) using a 40x oil objective (Nikon, Japan). The resulting images were analyzed through MetaFluor Software (Universal Imaging, Bedford Hills, NY, USA). For experiments using fura-2/AM, the ratio between fluorescence after excitation at 340 and $380 \mathrm{~nm}$ was calculated, whereas for experiments using GECI the fluorescence of the CEPIA indicators at a given time point was normalized to the initial fluorescence $\left(F / F_{0}\right)$. Ratiometric fluorescence values were obtained using the MetaFluor software and selecting individual cells (ROI). Two to four coverslips with 15 to 25 cells per coverslip were analyzed for each condition. Data values were further analyzed with GraphPad Prism 6.

\section{Plasmid transfection and siRNA silencing}

Cells were transfected with plasmids using Lipofectamine 2000 (Thermo Fisher Scientific) while transfection with siRNA to achieve silencing was accomplished with Lipofectamine RNAiMAX (Thermo Fisher Scientific). Briefly, lipofectamine and DNA or siRNA were added to medium without FBS and antibiotics. This solution was kept at room temperature for $20 \mathrm{~min}$ and administered to the cells. After $5 \mathrm{~h}$, the medium was replaced by growth medium. The quantities of lipofectamine and DNA or siRNA were: $9 \mu \mathrm{L}$ of lipofectamine and $2.5 \mu \mathrm{g} /$ mL GECI plasmids; $12 \mu \mathrm{L}$ of lipofectamine and $4.5 \mu \mathrm{g} /$ $\mathrm{mL}$ of $A P O E$ plasmids (described in [50]), and $4.5 \mu \mathrm{L}$ of lipofectamine and $1 \mu \mathrm{g} / \mathrm{mL}$ of APOE siRNA (s194291, Thermo Fisher Scientific) or negative control $1 \mu \mathrm{g} / \mathrm{mL}$ siRNA (Thermo Fisher Scientific).

\section{Lysosomal pH measurement}

Lysosomal $\mathrm{pH}$ was measured using the ratiometric dye LysoSensor Yellow/Blue DND-160 (Thermo Fisher Scientific) as described [51] with minor modifications. Briefly, cells were incubated with $2 \mu \mathrm{M}$ of LysoSensor Yellow/Blue in an isotonic solution with addition of $10 \%$ FBS. Next, cells were incubated with either additional isotonic solution for $\mathrm{pH}$ measurement, or with $\mathrm{pH}$ calibration buffers with the corresponding FBS content to perform a standard curve for each condition. $15 \mu \mathrm{M}$ of monensin and $30 \mu \mathrm{M}$ of nigericin were added to the $\mathrm{pH}$ calibration solutions to force lysosomal $\mathrm{pH}$ to equilibrate with a range of $\mathrm{pH}$ values (solutions at 4.0, 4.5, 5.0, 5.5 and $6.0 \mathrm{pH}$ ). Fluorescence was measured with a GENios Pro Fluorometer, and recorded using the XFluor4GENiosPro software package (TECAN). Lysosomal $\mathrm{pH}$ was determined from the ratio of excitation light at $340 \mathrm{~nm}$ and $390 \mathrm{~nm}$ (collection emission at $535 \mathrm{~nm}$ ) after extrapolation with the standard curve.

\section{Immunocytochemistry}

Cells were fixed with $4 \%$ paraformaldehyde for $15 \mathrm{~min}$ and permeabilized by adding $0.1 \%$ of Triton buffer. Then, $5 \%$ of normal goat serum (NGS) was used to block the unspecific unions. Primary antibodies (mouse monoclonal anti-ApoE (sc53570, Santa Cruz Biotechnology, dilution 1:400) and rat monoclonal anti-Lamp1 (1D4B, Hybridoma Bank, dilution 1:200) were incubated overnight, followed by one-hour incubation with the secondary antibody Cy3-donkey anti-rat IgG (712-165-150, Jackson Immunoresearch, dilution 1:200) and Alexa fluor 488 goat anti-mouse IgG (A11029, Thermo Fisher Scientific, dilution 1:1000). Coverslips were mounted on a slide with Fluoromount G. Images were acquired with confocal laser scanning microscopy ZEISS LSM 700. Analysis of lysosome localization was carried out using the ImarisCell tool of IMARIS software (Bitplane), which permits manual selection of the nucleus and the membrane of each cell and computes the distance $(\mu \mathrm{m})$ from each Lamp1-positive vesicle to the nucleus center. Lamp1-positive vesicles larger than $0.5 \mu \mathrm{m}$ were considered. The frequency distribution of vesicles from the nucleus center to the cellular membrane was represented. 


\section{Cholesterol staining}

Filipin III (Sigma-Aldrich) was used to stain cholesterol. Cells were fixed with $4 \%$ paraformaldehyde for $15 \mathrm{~min}$ and incubated with $25 \mu \mathrm{g} / \mathrm{mL}$ Filipin for $30 \mathrm{~min}$ at room temperature in the dark. Images were acquired with a CCD ORCA-EG monochromatic camera (Hamamatsu) and the Eclipse TE-2000E (Nikon) epifluorescence microscope, using a $20 \mathrm{x}$ objective.

\section{Lysosomal isolation}

Lysosomes from astrocytes were isolated as described [52]. Briefly, collected cells were washed in sucrose 0.25 $\mathrm{M}$ ( $\mathrm{pH}$ 7.2) and disrupted in a nitrogen cavitation chamber (Kontes Glass Company), followed by homogenization in a Teflon-glass homogenizer and centrifuging ( $2500 \mathrm{xg}$ for $15 \mathrm{~min}$ ). The mitochondrialysosomal-enriched faction was collected after 17,000 xg centrifugation. The lysosomal-mitochondrial-enriched fraction was then loaded in two subsequent discontinuous metrizamide/sucrose/percoll density gradients from which lysosomal pure fractions were isolated [52]. Lysosomes were broken by 5 consecutive freeze/thaw cycles and after centrifugation at $100.000 \mathrm{xg} 30 \mathrm{~min}$, lysosomal membrane and intralysosomal content were collected separately. The former pool was used for lipidomic analysis.

\section{Lipidomics}

The extraction of metabolites for the untargeted lipidomic assay was carried out by adding $200 \mu \mathrm{L} \mathrm{CHCl}_{3}$ : $\mathrm{MeOH}$ in a proportion of 1 to 2 with $0.1 \%$ formic acid to promote the ionization of molecules. Then, samples were vortexed, centrifuged at $4000 \mathrm{rpm}$, and analyzed with mass spectrometry using the QSTAR XL hybrid system (Applied Biosystems, Foster City, CA, USA). The sample was injected at a flux of $15 \mu \mathrm{L} / \mathrm{min}$ through the infusion integrated pump. Spectra were acquired during positive ionization in a range of $\mathrm{m} / \mathrm{z}$ from 50 to 1100 uma. The ionization parameters were: $3300 \mathrm{~V}$ of voltage ion spray, $60 \mathrm{~V}$ of decluttering potential, and $250 \mathrm{~V}$ of focusing potential. Nitrogen was used as a collision gas for the spectra acquisition. Markerview ${ }^{\mathrm{Tm}}$ and SIMCA-P ${ }^{\mathrm{mt}}$ software were used to reduce the results into a twodimensional matrix of peak spectra and intensity of peaks, and for the statistical analysis. Inter-genotype comparisons were carried out with the multivariate analysis Partial Least Squares-discriminant analysis (PLS-DA). Next, the Variable Importance in Projection (VIP) was used to establish which metabolites had more impact in the segregation of samples according to $A P O E 3$ and APOE4 genotypes. ANOVA with a Tukey correction post-test was applied to the group of metabolites with a VIP $>1$ to assess, again, inter-genotype differences with the identified metabolites. We then proceeded to identify metabolites with VIP $>1$ comparing their accurate masses with those available in metabolomics databases (HMDB, METLIN, KEGG and LIPIDMAPS) [53]. Finally, fold changes of identified metabolites in $A P O E 4$ vs $A P O E 3$ astrocytes were calculated and a multi-t statistical test with corrected probability (False Discovery Rate -FDR- 5\%) was applied.

\section{Western blot}

Cells for protein extraction were lysed with RIPA buffer and extracts were sonicated and centrifuged. Protein extracts were quantified with BCA kit $(23,225$, Thermo Fisher Scientific) according to the manufacturer's protocol. $20 \mu \mathrm{g}$ protein of samples was loaded in $12 \%$ polyacrylamide gels electrophoresis (PAGE). Electrophoresis was conducted at a constant amperage $(30 \mathrm{~mA})$ for approximately $2 \mathrm{~h}$ followed by the protein transference to a PVDF membrane at constant voltage $(100 \mathrm{mV})$ for $1.5 \mathrm{~h}$. $5 \%$ non-fat milk was used to block unspecific unions, and the primary antibodies mouse monoclonal anti- $\mathrm{V}$ ATPase subunit $\mathrm{V}_{0} \mathrm{D}_{1}$ (ab56441, Abcam, used at $2.5 \mu \mathrm{g} /$ $\mathrm{mL}$ ) and monoclonal anti $\beta$-actin (a5316, SigmaAldrich, used at 1/20000), were incubated overnight. The next day, the secondary antibody was incubated for $1 \mathrm{~h}$ (goat anti-mouse IgG: 31430, Thermo Fisher Scientific, used at 1/10000). Finally, the membrane was developed using the chemiluminescence kit of BioRad according to the manufacturer's protocol, and membrane chemiluminescence was detected with a Chemidoc MP Image System (BioRad). Image lab software (BioRad) was used for the quantification of bands.

\section{Measurement of mRNA expression}

Cells were collected adding Trizol Reagent. Then, 0.2 $\mathrm{mL}$ chloroform was added to the extracts, and these were centrifuged at $11,500 \mathrm{rpm}$ for $15 \mathrm{~min}$ at $4{ }^{\circ} \mathrm{C}$ allowing the formation of three phases. The RNA-containing phase (superior phase) was isolated by pipetting carefully, and $0.2 \mathrm{~mL}$ of isopropanol was added to precipitate of RNA, which was then washed with cold ethanol 75\%. RNA-sample concentration was determined with a Nanodrop 200 spectrophotometer (Thermo Fisher Scientific). $2 \mu \mathrm{g}$ of RNA was reverse transcripted to cDNA using $1 \mu \mathrm{M}$ of oligo DT, $1 \mu \mathrm{M}$ of hexamers, 0.5 mM dNTPs, 0.45 mM DTT, 10 U RNAse out, RT buffer, and $200 \mathrm{U}$ of retrotranscriptase. The PCR program was divided into four steps: $65^{\circ} \mathrm{C}$ for $10 \mathrm{~min}, 25^{\circ} \mathrm{C}$ for 10 min, $42^{\circ} \mathrm{C}$ for $1 \mathrm{~h}$, and $72{ }^{\circ} \mathrm{C}$ for $10 \mathrm{~min}$.

Gene expression was carried out with quantitative real-time PCR (qPCR) using Taqman and SYBR green technology. Fluorescence was detected with the 7500 Fast Real-Time PCR System. qPCR cycles were the following: a holding stage of $50{ }^{\circ} \mathrm{C}(2 \mathrm{~min}), 10 \mathrm{~min}$ at $95^{\circ} \mathrm{C}$ and 40 cycles of $95^{\circ} \mathrm{C}(15 \mathrm{~s})$, and $60^{\circ} \mathrm{C}(1 \mathrm{~min})$. A similar 
protocol was used for SYBR assay but with an extra stage for the melting curve $\left(15 \mathrm{~s}\right.$ at $95^{\circ} \mathrm{C}, 1 \mathrm{~min}$ at $60^{\circ} \mathrm{C}$, $30 \mathrm{~s}$ at $95^{\circ} \mathrm{C}$, and $15 \mathrm{~s}$ at $60^{\circ} \mathrm{C}$ ). Data analysis was performed using $\mathrm{Cq}$ value, and the average of the gene efficiency provided by LinReg PCR software, following the formula $1+$ eficience $^{\Lambda \mathrm{Cq}}$ of each gene analyzed. Expression data were normalized with housekeeping genes (Gapdh and/or18s), using their geometric mean calculated according to the geNorm algorithm [54]. TaqMan primers of APOE (Hs00171168_m1), Trpml (Mm00522550_m1), Gapdh (Mm9999915_g1), and 18S (Mm03928990) were purchased from Thermo Fisher Scientific. Primers for SYBR green were designed according to the sequence of the gene: Tpc1 ( $5^{\prime}$-CTGG GAGAGATGAATTATCAAGAG-3'; 5' -GTTGTGTACGAAGAGGTAGG-3'), Tpc2 (5'GCTGAGCCTTGCTT GTGAGG-3'; 5' -ACACTTCAGGGTCTTCTTCATCA3'), and Gapdh (5'-AAGCTCATTTCCTGGTATGAC3'; 5' -TGGTCCAGGGT TTCTTACTC-3').

\section{Statistical analysis}

Each determination was carried out with cells from at least three different passages. A parametric unpaired Ttest was used for the comparison of a given variable in two different conditions or cell types, whereas one-way or two-way analysis of variance (ANOVA), with a Tukey's or Dunn's post hoc test, was used when comparing more than two conditions. The software employed was GraphPad Prism 6, and data are represented as mean \pm SEM (standard error of the mean). A $p$-value $<0.05$ was considered significant ( $p$-value $<0.05\left(^{*}\right), p$-value $<0.01\left(^{(* *)}\right), p$ value $<0.001{ }^{(* * * *)}$ and $p$-value $<0.0001{ }^{(* * * * *)}$.

\section{Results}

\section{APOE4 expression alters astrocytic excitability}

To determine whether expression of the allele APOE4 alters astrocyte excitability, we recorded $\mathrm{Ca}^{2+}$ in hippocampal slices of 9-12-week-old male and female mice in which the endogenous mouse $A P O E$ gene had been replaced with human $A P O E 3$ or APOE4 genes. Recordings were made in ACSF medium supplemented with $10 \%$ FBS, in order to keep lipoprotein and lipid concentration as close as possible to physiological conditions. Slices were incubated with the $\mathrm{Ca}^{2+}$ indicator fluo-4/AM and the astrocytic marker sulforhodamine (SR101) (Fig. 1a, see Materials and methods). We analyzed $\mathrm{Ca}^{2+}$ spontaneous activity-that is, $\mathrm{Ca}^{2+}$ events at rest conditions-and neurotransmitter-induced $\mathrm{Ca}^{2+}$ responses in cells colabeled with Fluo-4/AM and SR101. To study spontaneous activity, we recorded APOE3 and APOE4 astrocytes for $120 \mathrm{~s}$. For receptor-mediated $\mathrm{Ca}^{2+}$ responses, we recorded basal peak activity for $30 \mathrm{~s}$, and then we stimulated slices with $1 \mathrm{mM}$ ATP. We selected purinergic stimulation because it elicits $\mathrm{Ca}^{2+}$ signals both in astrocytes in vivo and in vitro, triggering several physiological functions [34, 55], and because responses elicited by stimulation of purinergic receptors are the cause of $\mathrm{Ca}^{2+}$ hyperactivity in AD mouse models [56].

In male mice, we detected increased amplitude of spontaneous $\mathrm{Ca}^{2+}$ transients in APOE4 vs APOE3 astrocytes (Fig. 1b). Regarding induced activities, purinergic stimulation caused in both genotypes the increase in magnitude and frequency of $\mathrm{Ca}^{2+}$ transients typically seen in astrocytes. The amplitude of $\mathrm{Ca}^{2+}$ responses was greater in APOE4 cells than in APOE3 cells (Fig. 1c and d). Further, the magnitude of $\mathrm{Ca}^{2+}$ responses decreased after removal of ATP (post ATP phase) to basal levels in $A P O E 3$ astrocytes, but remained significantly increased over its own basal levels, and with respect to $A P O E 3$ cells, in APOE4 cells (Fig. 1c and d). The frequency of $\mathrm{Ca}^{2+}$ responses was similar in both genotypes, in both the ATP and post-ATP phases. It is worth stressing that the amplitude of spontaneous $\mathrm{Ca}^{2+}$ transients was also statistically increased in APOE4 compared to APOE3 cells in these set of experiments, confirming the results of the 120-s recordings (Fig. 1c and d).

Female mice differed from males in two respects. First, the amplitude of spontaneous and ATP-induced events was significantly increased $(p<0.001)$, by at least 2 -fold, in astrocytes from $A P O E 3$ females as compared to APOE 3 males (compare Fig. $1 \mathrm{~b}$ with $2 \mathrm{a}$ and $1 \mathrm{~d}$ with $2 \mathrm{c}$ ). Second, no differences were observed between $A P O E 3$ and APOE4 astrocytes in females in the magnitude of spontaneous and induced events (Fig. 2a-c). This may suggest that $\mathrm{Ca}^{2+}$ responses in astrocytes from $A P O E 3$ females represented the maximal $\mathrm{Ca}^{2+}$ response that could not increase further. Altogether, the ex vivo observations suggest that expression of human $A P O E$ alleles modulates $\mathrm{Ca}^{2+}$ transients in astrocytes in a sex-specific manner, such that expression of the APOE3 allele in male mice results in globally decreased $\mathrm{Ca}^{2+}$ transients in astrocytes-or expression of $A P O E 3$ in females in a global increase-as compared to the APOE4 allele.

\section{Immortalized APOE4 astrocytes show increased $\mathrm{Ca}^{2+}$ mobilization from acidic stores}

To gain insight into the mechanism by which expression of different $A P O E$ alleles regulates $\mathrm{Ca}^{2+}$ transients in astrocytes, we used immortalized astrocytes that express human APOE3 or APOE4 [44] since this in vitro model allows for experimental manipulations that are not feasible in brain slices. As with slices, cells were supplemented with $10 \% \mathrm{FBS}$, in order to keep lipoprotein and lipid concentration as close as possible to physiological conditions. It is worth stressing that immortalized astrocytes are aneuploid so the sexual identity is lost. Thus, a key question was whether their $\mathrm{Ca}^{2+}$ phenotype is maleor female-like. Our data show that they reproduce a 


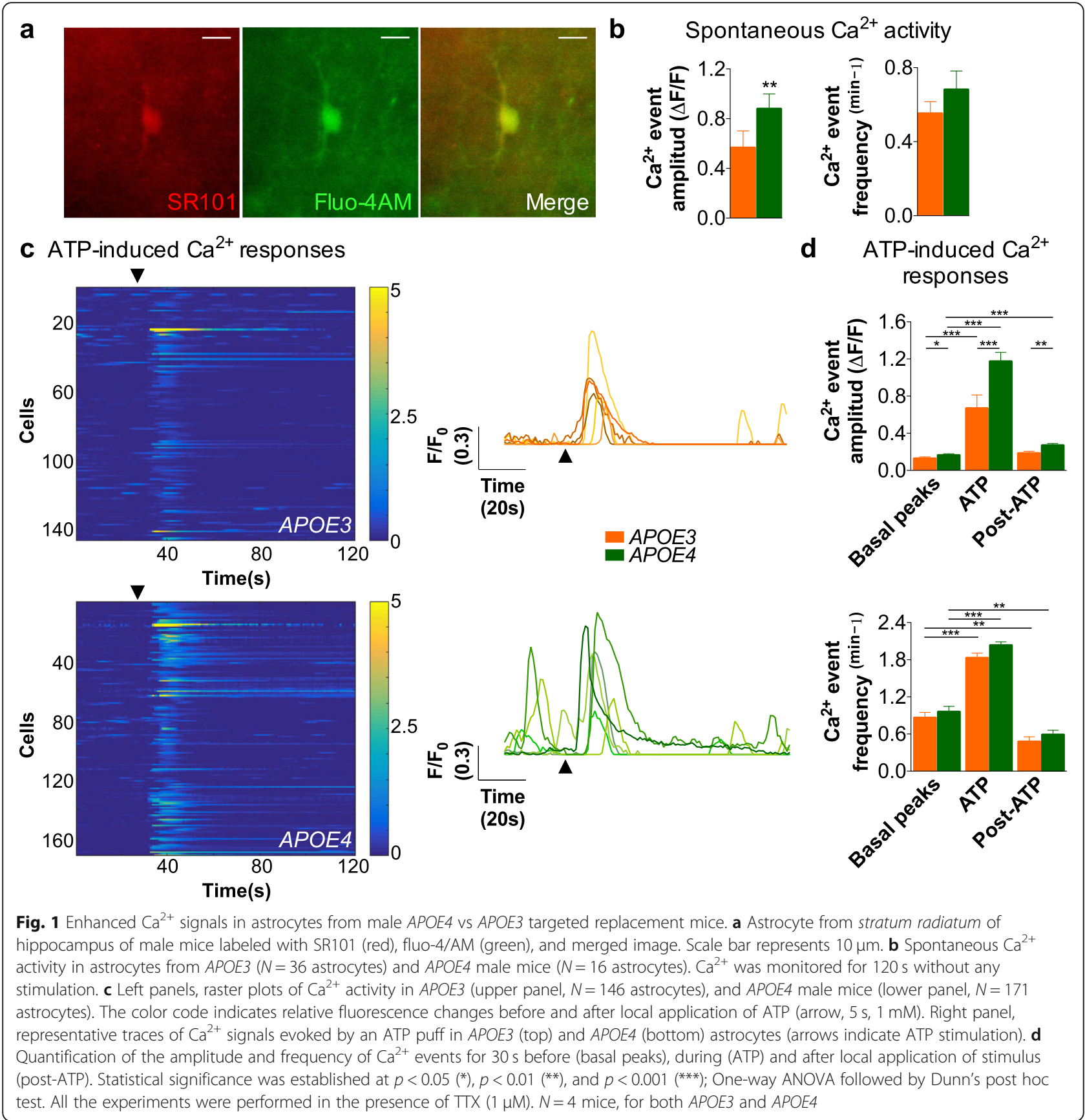

male-like $\mathrm{Ca}^{2+}$ signaling phenotype in the presence of lipids. First, differences in $\mathrm{Ca}^{2+}$ responses at rest showed the same trend observed in male mice. APOE4 astrocytes had significantly different $\mathrm{Ca}^{2+}$ basal levels than $A P O E 3$ astrocytes ( $p$-value $=0.01$ ), the fluorescence ratio being $0.28 \pm 0.01$ and $0.41 \pm 0.03$, respectively (Fig. 3a-c). Note that cultured astrocytes do not show at rest the so-called spontaneous $\mathrm{Ca}^{2+}$ oscillations observed ex vivo, but stable basal $\mathrm{Ca}^{2+}$ levels that we could compare thanks to the ratiometric fura-2/AM $\mathrm{Ca}^{2+}$ indicator. Second,
$100 \mu \mathrm{M}$ ATP stimulation resulted in greater $\mathrm{Ca}^{2+}$ responses in APOE4 than in APOE3 astrocytes (Fig. 3a). Purinergic-induced $\mathrm{Ca}^{2+}$ responses also lasted longer: the response was $64.9 \pm 8.2 \%$ of the maximum peak signal after $20 \mathrm{~s}$ in APOE4 cells but only $27.7 \pm 1.5 \%$ in $A P O E 3$ astrocytes. Moreover, altered $\mathrm{Ca}^{2+}$ signaling was not restricted to purinergic stimulation, as adrenergic and muscarinic-receptor activation also triggered greater cytosolic $\mathrm{Ca}^{2+}$ responses in APOE4 than in APOE3 astrocytes (Fig. $3 \mathrm{~b}$ and $\mathrm{c}$ ). Importantly, the magnitude of 


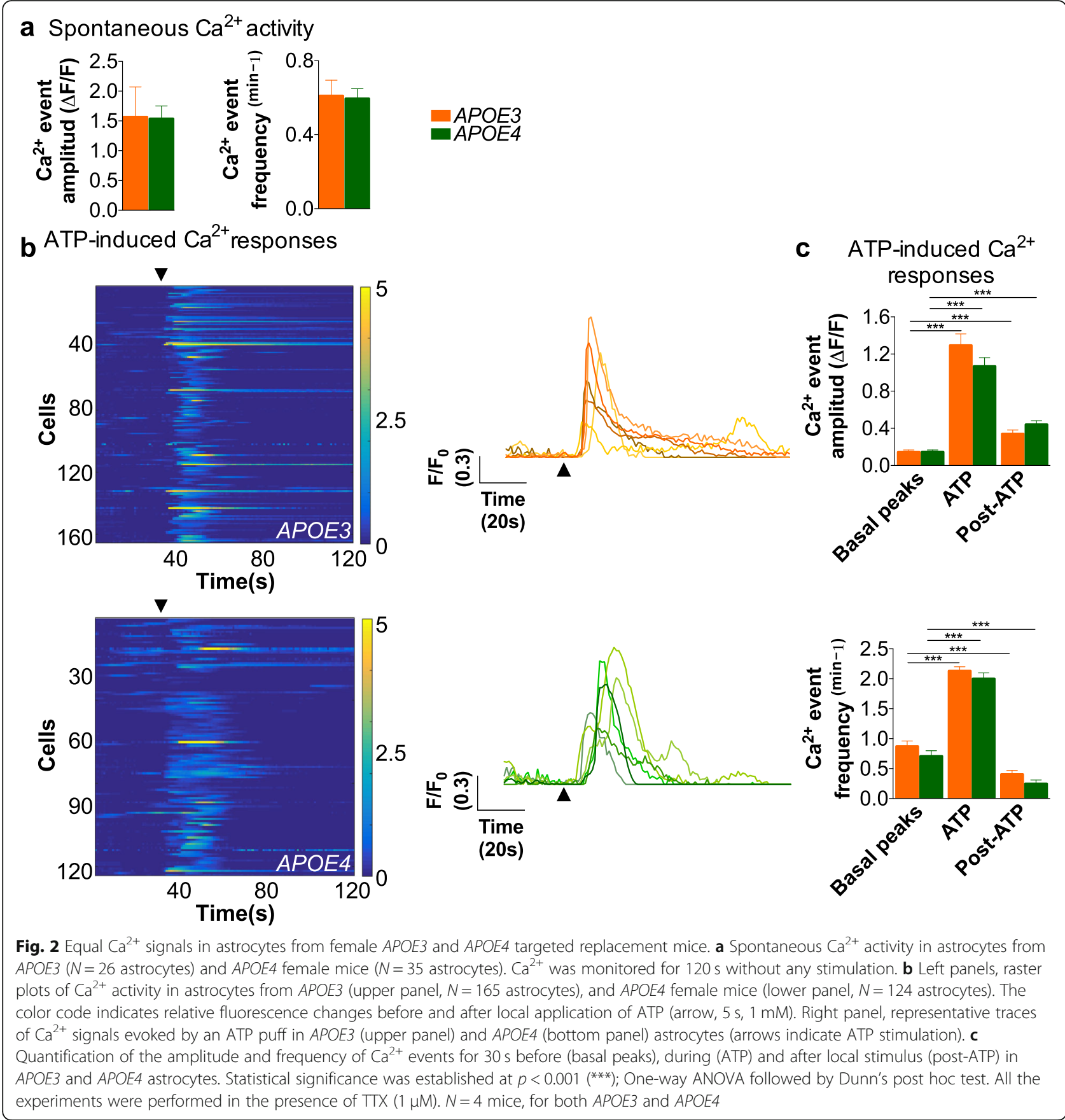

purinergic-induced $\mathrm{Ca}^{2+}$ responses was the same with two other FBS batches (peak responses after stimulation with $100 \mu \mathrm{M}$ ATP were $0.36 \pm 0.13$ in $A P O E 3$ and $0.94 \pm$ 0.01 in APOE4; and $0.37 \pm 0.04$ in APOE3 and $0.91 \pm$ 0.05 in APOE4 astrocytes). Taken together, the data support immortalized $A P O E 3$ and $A P O E 4$ astrocytes as a model to study the mechanisms underlying the regulation of $\mathrm{Ca}^{2+}$ responses by APOE alleles in males.

Next, in order to identify which pathways are dysregulated in APOE4 astrocytes, we examined $\mathrm{Ca}^{2+}$ fluxes among the principal intracellular $\mathrm{Ca}^{2+}$ sources with organelle-specific probes and pharmacological manipulations. First, we investigated the mitochondrial $\mathrm{Ca}^{2+}$ uptake that characteristically buffers increases in cytosolic $\mathrm{Ca}^{2+}$. Since $A P O E 4$ has been described as harming mitochondria in neurons [57], we reasoned that harmed mitochondria in APOE4 astrocytes could result in deficient $\mathrm{Ca}^{2+}$ uptake, and hence in increased intracellular $\mathrm{Ca}^{2+}$ responses. However, expression of the mitochondrial $\mathrm{Ca}^{2+}$ indicator CEPIA3mt (Fig. 3d) showed higher 


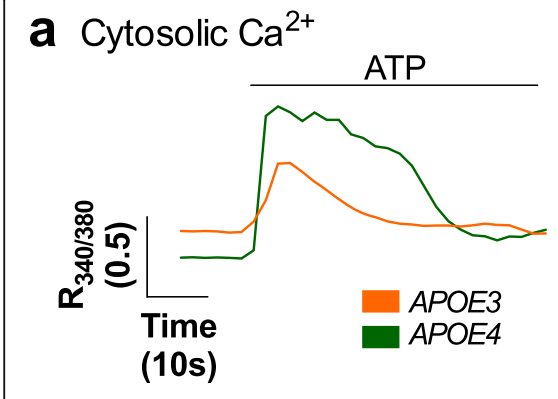

C Cytosolic $\mathrm{Ca}^{2+}$

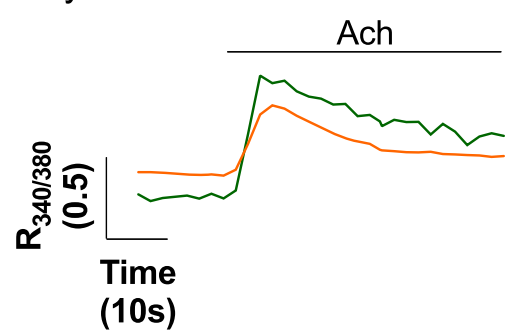

e Mitochondrial $\mathrm{Ca}^{2+}$

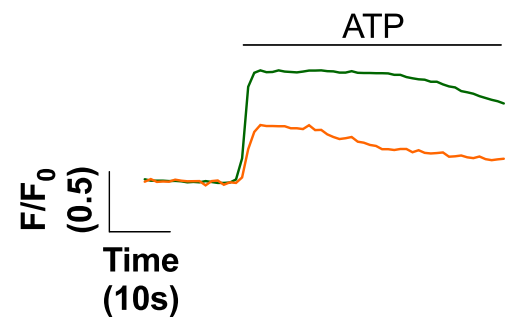

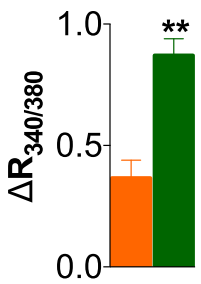
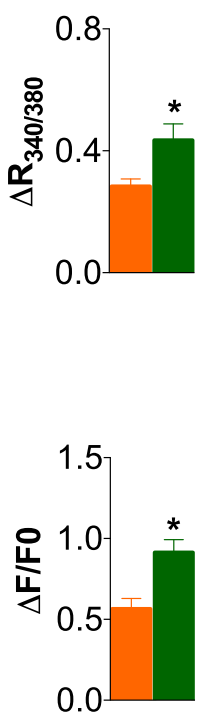

\section{b Cytosolic $\mathrm{Ca}^{2+}$}
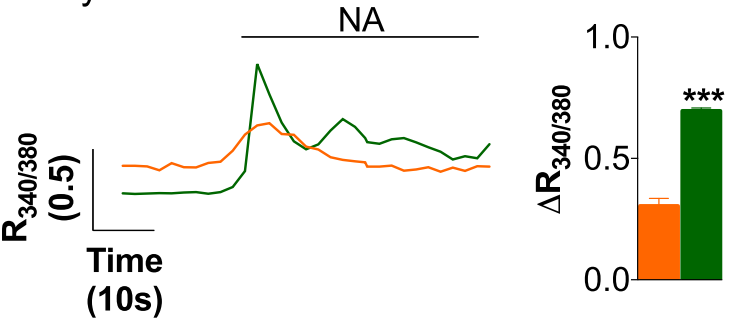

d
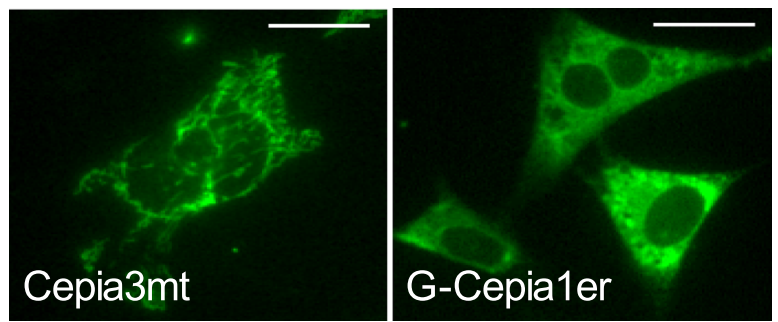

f $\mathrm{ER} \mathrm{Ca}^{2+}$
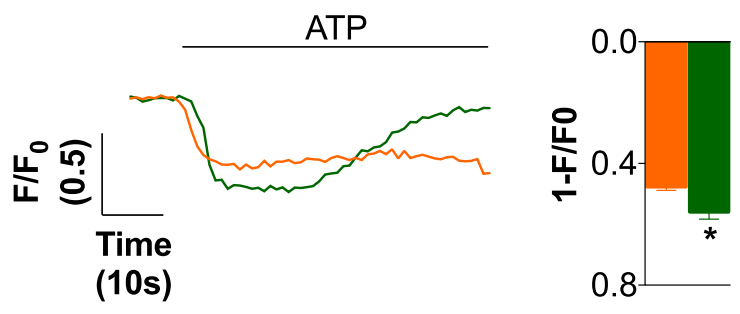

Fig. 3 Enhanced $\mathrm{Ca}^{2+}$ signals in immortalized astrocytes from APOE4 vs APOE3 targeted replacement mice. $\mathrm{Ca}^{2+}$ responses measured using fura2/AM in APOE3 and APOE4 astrocytes after stimulation with (a) $100 \mu \mathrm{M}$ ATP, (b) $10 \mu \mathrm{M}$ noradrenaline (NA), and (c) $100 \mu \mathrm{M}$ acetylcholine (Ach). Representative traces and quantification of the magnitude of the responses are shown ( $N=4$ for $\mathbf{a}$ and $\mathbf{c}$, and $N=3$ for $\mathbf{b}$ ). $\mathbf{d}$ Images of astrocytes transfected with the $\mathrm{Ca}^{2+}$ probes for mitochondria (CEPIA3mt) and ER (G-CEPIA1er). Scale bar represents $15 \mu \mathrm{m}$. e Representative traces and quantification of mitochondrial $\mathrm{Ca}^{2+}$ in APOE3 and APOE4 cells transfected with CEPIA3mt upon stimulation with ATP $(N=3)$. $\mathbf{f}$ Representative traces and quantification of the decrease in ER $\mathrm{Ca}^{2+}$ upon stimulation of purinergic receptors in APOE3 and APOE4 cells transfected with GCEPIA1er $(N=5)$. Unpaired parametric T-test was used to compare responses in APOE3 vs APOE4 astrocytes. $p<0.05\left({ }^{*}\right), p<0.01\left(^{* *}\right)$, $p<0.001{ }^{(* *)}$

$\mathrm{Ca}^{2+}$ uptake in $A P O E 4$ mitochondria compared to $A P O E 3$ astrocytes, consistent with the higher ATPinduced $\mathrm{Ca}^{2+}$ responses in the cytosol (Fig. 3e). Second, we studied the main $\mathrm{Ca}^{2+}$ signaling pathway in astrocytes, $\mathrm{Ca}^{2+}$ mobilization from the ER through the IP3 receptor, by transfecting cells with G-CEPIA1er (Fig. 3d), and directly measuring $\mathrm{Ca}^{2+}$ contents inside this organelle. As expected, $100 \mu \mathrm{M}$ ATP decreased $\mathrm{Ca}^{2+}$ levels in the ER of both $A P O E 3$ and APOE4 astrocytes, indicative of $\mathrm{Ca}^{2+}$ being released to the cytosol. Since the process is, although significantly, just slightly reinforced in APOE4 astrocytes (Fig. 3f), the greater cytosolic $\mathrm{Ca}^{2+}$ responses in these cells could not rely exclusively on increased $\mathrm{Ca}^{2+}$ mobilization from the ER. Third, we explored $\mathrm{Ca}^{2+}$ mobilization from acidic stores, which are mainly lysosomes and related organelles [58] that we have shown to be involved in purinergic-induced $\mathrm{Ca}^{2+}$ responses in astrocytes [37]. Figure 4a shows the main $\mathrm{Ca}^{2+}$ fluxes in lysosomes. We recorded cytosolic $\mathrm{Ca}^{2+}$ with fura-2/AM, after inhibiting $\mathrm{Ca}^{2+}$ release from acidic stores with $100 \mu \mathrm{M}$ of Ned-19, an inhibitor of NAADP receptors responsible for $\mathrm{Ca}^{2+}$ release from these organelles [59]. Control cells were treated with DMSO, the vehicle of Ned-19. As expected, Ned-19 reduced ATPinduced $\mathrm{Ca}^{2+}$ responses in APOE3 cells (Fig. 4b), confirming the contribution of lysosomal $\mathrm{Ca}^{2+}$ to cytosolic transients [37]. Interestingly, Ned-19 greatly reduced $\mathrm{Ca}^{2+}$ responses in APOE4 astrocytes, such that purinergic-mediated $\mathrm{Ca}^{2+}$ responses in the presence of Ned-19 were of similar magnitude in both cell types. 


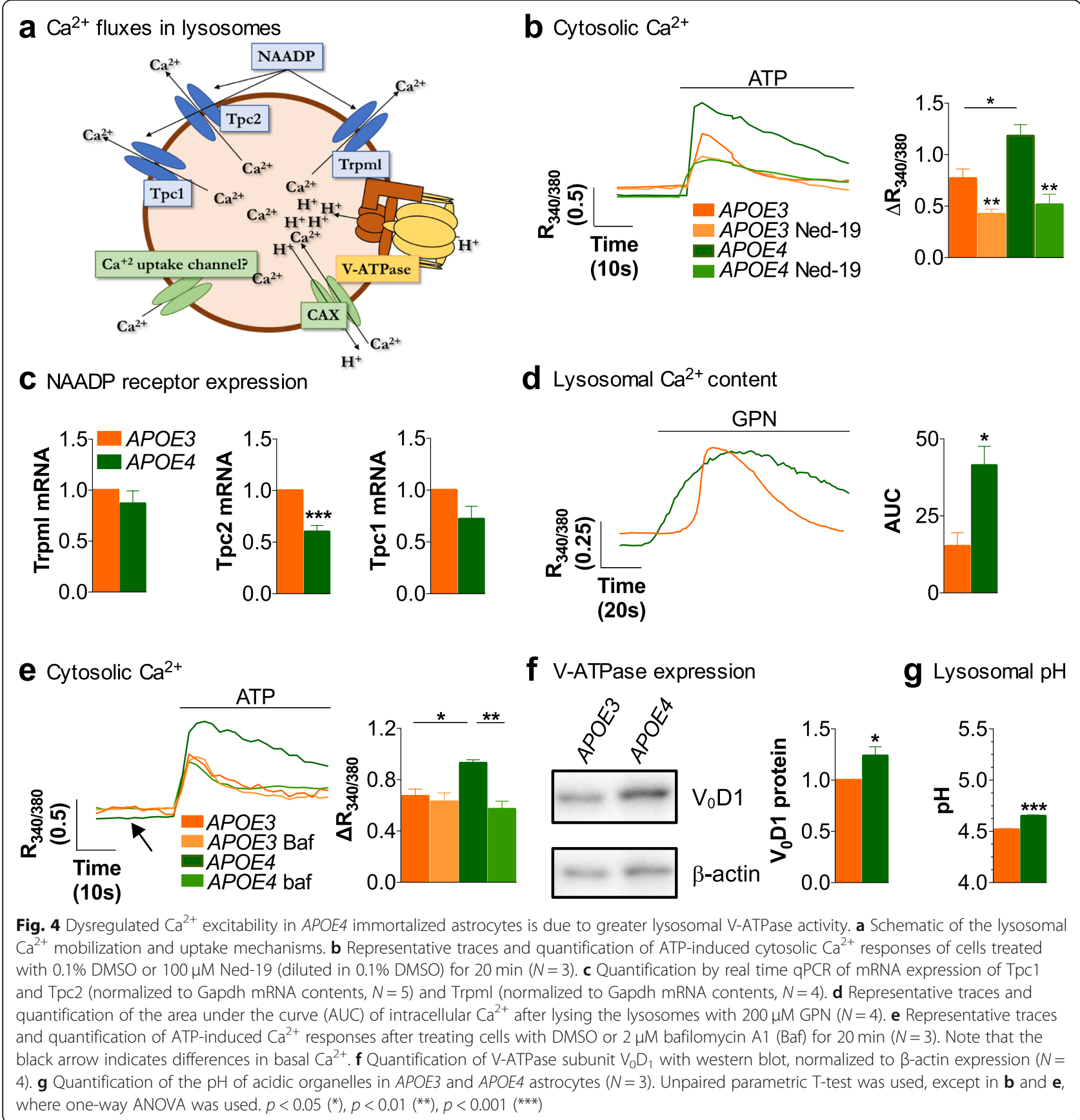

Hence, $\mathrm{Ca}^{2+}$ release from acidic-stores appears to be responsible for the greater purinergic-elicited $\mathrm{Ca}^{2+}$ responses in APOE4 astrocytes. Altogether, our results thus far lend support to the idea that lysosomal-related $\mathrm{Ca}^{2+}$ release is the main $\mathrm{Ca}^{2+}$ signaling pathway dysregulated in $A P O E 4$ astrocytes.

Dysregulation of V-ATPase activity contributes to the alteration of $\mathrm{Ca}^{2+}$ responses in APOE4 astrocytes $\mathrm{Ca}^{2+}$ is released from acidic stores upon stimulation of NAADP receptors, which are $\mathrm{Ca}^{2+}$ channels, the most accepted candidates being two-pore channels 1 and 2 (Tpc1, Tpc2), and transient receptor potential mucolipin (Trpml) [59]. By contrast, $\mathrm{Ca}^{2+}$ uptake by acidic stores is accomplished through an indirect mechanism whereby $\mathrm{V}$-ATPase pumps $\mathrm{H}^{+}$into the vesicles, and then $\mathrm{H}^{+}$are exchanged with $\mathrm{Ca}^{2+}$ through the $\mathrm{Ca}^{2+} / \mathrm{H}^{+}$exchanger (CAX) [60] (Fig. 4a). Thus, greater $\mathrm{Ca}^{2+}$ release from acidic stores in APOE4 astrocytes might be due to two phenomena: greater expression or activation of NAADP receptors, or greater $\mathrm{Ca}^{2+}$ stored in these organelles, due to increased activity of V-ATPase and/or CAX. First, we 
analyzed the expression of NAADP receptors in astrocytes with real time qPCR. Expression of Trpml and Tpc1 channels is the same in APOE3 and APOE4 cells, while expression of Tpc2 channel is lower in APOE4 cells (Fig. 4c), perhaps as a result of a negative feedback mechanism in response to the high $\mathrm{Ca}^{2+}$ signals in $A P O E 4$ astrocytes. In any event, the increased release of $\mathrm{Ca}^{2+}$ from APOE4 lysosomes cannot be attributed to increased expression of NAADP receptors.

Second, we analyzed $\mathrm{Ca}^{2+}$ contents inside acidic stores with a protocol in which they were osmotically lysed due to the accumulation of the peptide Glycyl-L-phenylalanine 2-naphthylamide (GPN), followed by its proteolysis by cathepsin $\mathrm{C}$, such that the stored lysosomal $\mathrm{Ca}^{2+}$ is released into the cytoplasm. Then, the area under the curve (AUC) of the cytosolic $\mathrm{Ca}^{2+}$ increase after addition of GPN to the astrocytes was used to calculate the total amount of stored calcium in these organelles. The results showed greater AUC in APOE4 cells (Fig. 4d), supporting a higher concentration of lysosomal-related $\mathrm{Ca}^{2+}$ in APOE4 cells, as compared to $A P O E 3$. Since there are no pharmacological modulators of CAX, we relied on a pharmacological inhibitor of V-ATPase, bafilomycin A1, and on measurements of $\mathrm{pH}$ in acidic organelles, to establish the implication of the pump and CAX in the increased luminal $\mathrm{Ca}^{2+}$. Bafilomycin A1 increased basal cytoplasmic $\mathrm{Ca}^{2+}$ concentration in APOE4 astrocytes to $0.40 \pm 0.05$ (control values of astrocytes treated with vehicle were $0.30 \pm 0.01 ; p$-value $=0.05)$, whereas there was no effect on non-stimulated intracellular $\mathrm{Ca}^{2+}$ levels in APOE3 $(0.44 \pm$ 0.08 for cells treated with bafilomycin A1 compared to $0.39 \pm 0.02$ of cells treated with vehicle). This suggests that the aforementioned lower basal cytoplasmic $\mathrm{Ca}^{2+}$ concentration in APOE4 cells is due to greater V-ATPasemediated $\mathrm{Ca}^{2+}$ uptake into acidic stores, consistent with the greater intralysosomal $\mathrm{Ca}^{2+}$ levels revealed by the GPN experiments. Accordingly, bafilomycin A1 reduced the ATP-induced $\mathrm{Ca}^{2+}$ release in APOE4 astrocytes, confirming the dependence of these $\mathrm{Ca}^{2+}$ responses on acidic stores (Fig. 4e). In contrast, bafilomycin A1 did not change purinergic-induced $\mathrm{Ca}^{2+}$ responses in APOE3 astrocytes. Thus, both basal levels and ATP responses in the presence of bafilomycin A1 might indicate the existence of low VATPase activity in APOE3 astrocytes. Indeed, the expression of V-ATPase subunit $\mathrm{V}_{0} \mathrm{D}_{1}$, which is highly expressed in astrocytes [61], was higher in APOE4 cells than in APOE3 cells (Fig. 4f). Because V-ATPase controls the flow of $\mathrm{H}^{+}$into acidic stores, we analyzed the $\mathrm{pH}$ of acidic stores with the probe lysosensor and fluorometry. We found that both $A P O E 3$ and $A P O E 4$ astrocytes had standard lysosomal-related $\mathrm{pH}$, with a minimal but significant difference of $0.14 \mathrm{pH}$ units between genotypes, APOE4 lysosomes being more alkaline (Fig. $4 \mathrm{~g}$ ). If the $\mathrm{pH}$ does not decrease despite increased activity of the V-ATPase pump, it follows that CAX activity must be increased in APOE4 astrocytes, too, such that the increased number of $\mathrm{H}^{+}$ entering the acidic stores exit through CAX in exchange for $\mathrm{Ca}^{2+}$. As a result, lysosomal $\mathrm{Ca}^{2+}$ concentration and hence basal $\mathrm{Ca}^{2+}$ and purinergic-induced $\mathrm{Ca}^{2+}$ release from lysosomes, are greater in APOE4 than in APOE3 astrocytes. Note that we did not determine nor manipulate CAX expression in APOE3 and APOE4 cells because the sequence of mouse CAX is unknown.

\section{APOE3 expression in APOE4 astrocytes reduces cytosolic $\mathrm{Ca}^{2+}$ responses}

Is the effect of $A P O E 4$ due to: (1) loss-of-function due to decreased contents [62], (2) malfunction, (3) gain-oftoxic function because of its structure, or (4) misplaced intracellular localization? We first examined ApoE levels in immortalized $A P O E 3$ and $A P O E 4$ astrocytes by quantifying mRNA levels with qPCR. As shown in Fig. 5a, $A P O E$ expression is lower in $A P O E 4$ than in $A P O E 3$ astrocytes. Therefore, it is plausible that lower expression of APOE4 accounts for $\mathrm{Ca}^{2+}$ signaling alterations. To test this possibility, we modulated the quantity of $A P O E 3$ and $A P O E 4$ with the rationale that, if $A P O E$ expression matters, decreasing ApoE in APOE3 cells would increase $\mathrm{Ca}^{2+}$ responses, whereas increasing ApoE in $A P O E 4$ cells would decrease $\mathrm{Ca}^{2+}$ responses. Upon decreasing $A P O E$ expression in $A P O E 3$ astrocytes with an $A P O E$ siRNA (Fig. 5b), ATP-induced $\mathrm{Ca}^{2+}$ responses were still lower, as compared to APOE4 astrocytes, with no differences observed between scramble- and siRNAtransfected $A P O E 3$ cells (Fig. 5c). We also tried the opposite strategy: we increased $A P O E$ expression using GFP-APOE3 or GFP-APOE4 plasmids, which overexpress a GFP-ApoE fusion protein, which then allows one to identify cells with increased $A P O E$ expression (Fig. 5d). The GFP signal did not interfere with fura-2/AM (data not shown). Because transfection efficiencies were different among experiments (5 to 50\% of GFP transfected cells), we avoided inter-experimental variability by normalizing peak $\mathrm{Ca}^{2+}$ responses to levels recorded in $A P O E 3$ astrocytes transfected with a GFP-expressing plasmid without $A P O E$ constructs. The over-expression of GFP-APOE3, but not of GFP-APOE4, transformed $A P O E 4$ into $A P O E 3$ astrocytes, in a statistically significant manner (Fig. 5e), suggesting that $\mathrm{Ca}^{2+}$ hyperactivity in APOE4 astrocytes is mainly due to the expression of this particular isoform, but not to lower $A P O E$ expression. The data do not support, however, a gain of a toxic function by $A P O E 4$, because, if this were the case, $A P O E 4$-associated dysfunction would have been potentiated by GFP-APOE4 over-expression, and would not have been rescued by GFP-APOE3, since the toxic element, $A P O E 4$, remained. In agreement, there were no differences between ATP-induced $\mathrm{Ca}^{2+}$ signals in APOE3 
a $A P O E$ expression $\mathbf{b}$ ApoE expression

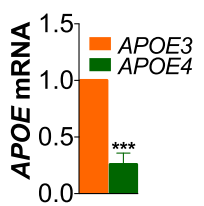

d
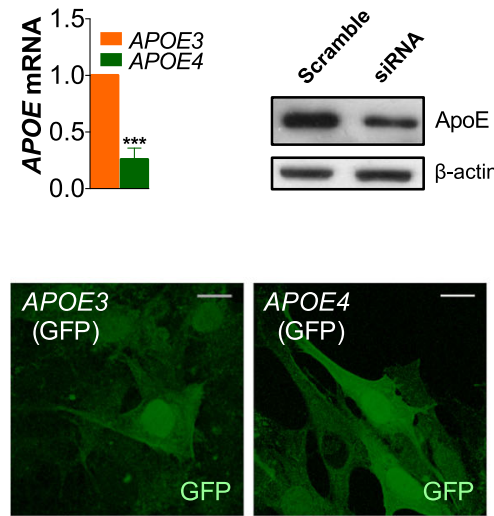

GFP
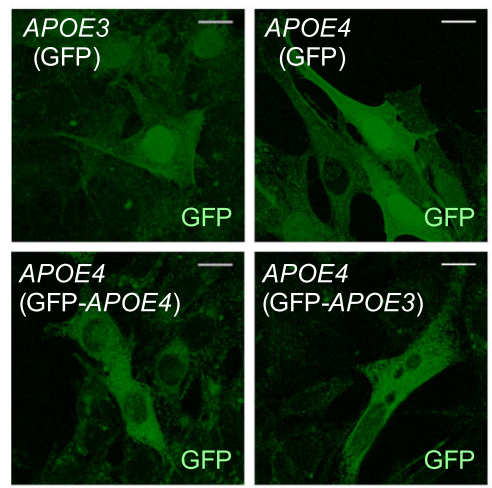

g ApoE localization
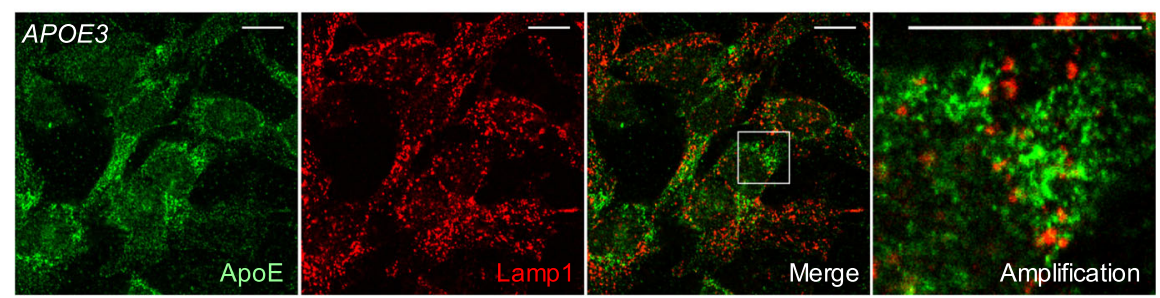

h ApoE localization
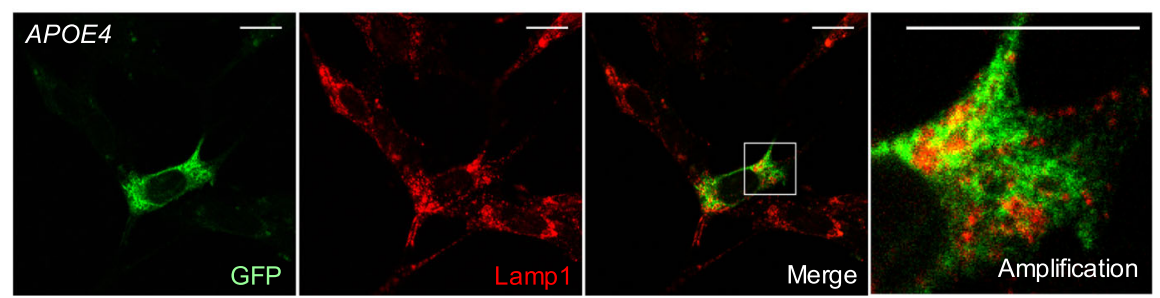

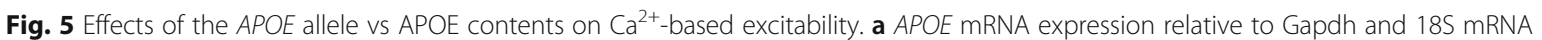
contents in APOE3 and APOE4 immortalized astrocytes, quantified by real time qPCR $(N=3)$. b Representative ApoE western blot of APOE3 cells transfected with scramble or APOE siRNA. c Representative traces and quantification of the magnitude of ATP-induced $\mathrm{Ca}^{2+}$ responses in $A P O E 3$ astrocytes transfected with lipofectamine (lipo), plus scramble (sc) or APOE siRNA, and APOE4 astrocytes treated only with lipofectamine ( $N=4)$. $\mathbf{d}$ Representative images of immunocytochemistry of APOE3 and APOE4 cells transfected with plasmids expressing GFP, GFP-APOE4, and GFP-APOE3, as indicated. Scale bar represents $15 \mu \mathrm{m}$. e Representative traces and quantification of the magnitude of $100 \mu \mathrm{M}$ ATP-elicited $\mathrm{Ca}^{2+}$ responses in APOE3 and APOE4 cells transfected with different plasmids as indicated. $\mathrm{Ca}^{2+}$ peaks after ATP stimulation are relative to the responses of APOE3 cells transfected with GFP. Only GFP fluorescent cells were analyzed (at least 30 cells from 4 independent experiments). $\mathbf{f}$ Quantification of the magnitude of $\mathrm{Ca}^{2+}$ responses elicited by $100 \mu \mathrm{M}$ ATP in APOE3 astrocytes transfected with GFP or GFP-APOE4 plasmids, as indicated. Ca ${ }^{2+}$ peaks after ATP stimulation are relative to the responses of APOE3 cells transfected with GFP. Only GFP fluorescent cells were analyzed (at least 30 cells from 4 independent experiments). $\mathbf{g}$ Representative images of Lamp1 (red) and ApoE (green) immunocytochemistry in APOE3 cells. Merged images and amplifications of the area in the white frame, are displayed. Scale bar represents $15 \mu \mathrm{m}$. $\mathbf{h}$ Representative images of Lamp1 immunocytochemistry (red) and GFP-ApoE fluorescence (green) in APOE4 cells. Merged images and the amplification of a cell of each image, indicated with a white frame, are displayed. Scale bar represents $15 \mu \mathrm{m}$. Unpaired parametric T-test was used in $\mathrm{a}$, and one-way ANOVA in $\mathrm{C}$ and e. $p<0.05\left(^{*}\right), p<0.01\left(^{* *}\right), p<0.001\left(^{* *}\right), p<0.0001{ }^{(* * *)}$ 
cells transfected with GFP-APOE4 or with GFP (Fig. 5f), again ruling out a toxic effect of $A P O E 4$. Taken together, our data support APOE4 malfunction rather than toxicity.

Finally, because acidic stores accounted for the differences in $\mathrm{Ca}^{2+}$ responses between genotypes, we studied whether ApoE was localized in the acidic stores. Because the quality of staining of such organelles with the fluorophore lysotracker was not optimal for confocal studies (data not shown), we resorted to using Lamp1, a marker for lysosomes, autophagosomes, and different vesicles of the endolysosomal pathway, including late-endosomes [63]. In $A P O E 3$ astrocytes, we used ApoE and Lamp-1 immunostaining (Fig. 5g). In $A P O E 4$ astrocytes, we relied on APOE4 overexpression with GFP-APOE4, since the low amounts of $A P O E$ expression in APOE4 cells precluded immunocytochemical analysis (Fig. 5h). We observed that neither ApoE3 nor ApoE4 from GFPAPOE4 colocalized with Lamp-1. These observations rule out the likelihood that the alterations in lysosomalrelated $\mathrm{Ca}^{2+}$ handling in APOE4 astrocytes are due to loss of a direct interaction of ApoE with channels mediating $\mathrm{Ca}^{2+}$ fluxes, suggesting, instead, indirect actions of the apolipoprotein, perhaps through changes in lipid homeostasis.

\section{ATP-induced $\mathrm{Ca}^{2+}$ responses are modulated by extracellular lipids in APOE3 but not APOE4 astrocytes}

Considering the wealth of evidence documenting how channels and pumps involved in $\mathrm{Ca}^{2+}$ signaling are regulated by lipids, particularly by membrane lipids $[64,65]$, we posited that lipids regulate $\mathrm{Ca}^{2+}$ fluxes in astrocytes, too, and that aberrant lipid homeostasis accounts for the observed dysregulation of $\mathrm{Ca}^{2+}$ fluxes in APOE4 astrocytes, particularly in lysosome-related organelles. Lipid modulation of $\mathrm{Ca}^{2+}$ transients in astrocytes is uncharted territory. Thus, to gain insight into the control of astrocyte excitability by lipids in the context of APOE4, we carried out two sets of experiments. First, we aimed to obtain proof-of-concept that lipids regulate $\mathrm{Ca}^{2+}$ transients in astrocytes, by examining the effect of changing lipid contents on the excitability of immortalized APOE3 and APOE4 astrocytes. Second, we analyzed cholesterol subcellular distribution, and we performed a lipidomic analysis of lysosomal and whole-membrane to identify candidates for excitability-modulating lipids, and changes thereof in the two genotypes.

Thus far, all our $\mathrm{Ca}^{2+}$ imaging experiments had been performed in medium supplemented with FBS, rich in nutrients, including lipoproteins. Here, we replaced this medium with three different media with lower lipid composition 2-5 min prior to $\mathrm{Ca}^{2+}$ imaging: 1) Krebs medium (KH), 2) DMEM supplemented with lipoproteins-deficient FBS and 3) DMEM with B27, a supplement without lipoproteins and restricted composition of lipids: linoleic acid, linolenic acid, progesterone, and corticosteroids. In the absence of lipids, nonstimulated basal $\mathrm{Ca}^{2+}$ levels were significantly lower in immortalized $A P O E 4$ vs $A P O E 3$ astrocytes, as detected in the presence of lipids. Thus, in $\mathrm{KH}$, basal levels were $0.29 \pm 0.02$ in $A P O E 3$ vs $0.23 \pm 0.03$ in APOE4 ( $p$-value $=$ $0.04)$; in DMEM supplemented with lipoproteindeficient FBS, $0.39 \pm 0.07$ in $A P O E 3$ vs $0.29 \pm 0.06$ in APOE4 (p-value $=0.04$ ); and in DMEM with B27, $0.30 \pm$ 0.02 in APOE3 vs $0.22 \pm 0.01$ in APOE4 (p-value = 0.007). By contrast, in all three conditions, stimulation of purinergic responses elicited $\mathrm{Ca}^{2+}$ responses of similar magnitude in $A P O E 3$ and APOE4 astrocytes (Fig. 6a-c, f). It was not the case that responses in $A P O E 4$ cells had diminished, but, rather, that responses had increased in $A P O E 3$ cells. That is, $A P O E 4$ astrocytes present the same magnitude of ATP-induced $\mathrm{Ca}^{2+}$ signals regardless of the lipids presents, whereas $A P O E 3$ astrocytes adapt their $\mathrm{Ca}^{2+}$ responses to the concentration of extracellular lipids, with responses being low in media rich in lipids (presence of FBS) and high in the presence of low lipid concentration, or no lipids. Consistent with the greater ATP-triggered $\mathrm{Ca}^{2+}$ responses, the responses also lasted longer in $A P O E 3$ astrocytes in the absence of lipids: the response was $36.0 \pm 4.0 \%$ of the maximum peak signal after $20 \mathrm{~s}$ in $\mathrm{KH}, 51.6 \pm 4.3 \%$ in DMEM supplemented with lipoproteins-deficient FBS and $34.6 \pm 3.0 \%$ in DMEM with B27, as compared to the previously reported $27.7 \pm 1.5 \%$ in DMEM with FBS $(p<0.05)$. Thus, the results point to a potentiation of long-lasting amplification $\mathrm{Ca}^{2+}$ pathways, perhaps by $\mathrm{Ca}^{2+}$-induced $\mathrm{Ca}^{2+}$ release from the ER or store-operated $\mathrm{Ca}^{2+}$ entry (SOCE)-that is, $\mathrm{Ca}^{2+}$ influx across the plasma membrane in response to depletion of intracellular $\mathrm{Ca}^{2+}$ stores. Still, ATP responses were significantly shorter ( $p$ value $<0.01)$ in lipid-depleted $A P O E 3$ astrocytes as compared to APOE4 astrocytes $(72.57 \pm 3 \%, 68.4 \pm 6.2 \%$ and $81.2 \pm 6.8 \%$ for APOE4 cells kept in KH, DMEM with lipoprotein-deficient FBS and DMEM with B27), indicating that some differences in $\mathrm{Ca}^{2+}$ fluxes remain between $A P O E 3$ and $A P O E 4$ astrocytes.

It is worth stressing that the increased ATP-induced $\mathrm{Ca}^{2+}$ response in $A P O E 3$ astrocytes is a fast-onset process, as it was observed just a few min after lipoprotein removal. It is not transient, because it persisted $12 \mathrm{~h}$ after replacement of DMEM supplemented with FBS for DMEM supplemented with B27 (Fig. 6d and f), and it is reversible, because it diminishes if the medium is replaced again by DMEM supplemented with FBS $5 \mathrm{~min}$ prior to $\mathrm{Ca}^{2+}$ recordings (Fig. 6e and f).

Altogether, three conclusions may be drawn from these results: they constitute the first demonstration that astrocyte excitability is modulated by lipids and/or 


\section{a Cytosolic $\mathrm{Ca}^{2+} / \mathrm{KH} 5 \min$}

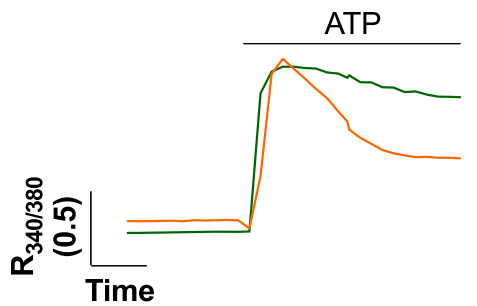

(10s)

\section{Cytosolic $\mathrm{Ca}^{2+} / \mathrm{B} 275 \mathrm{~min}$}

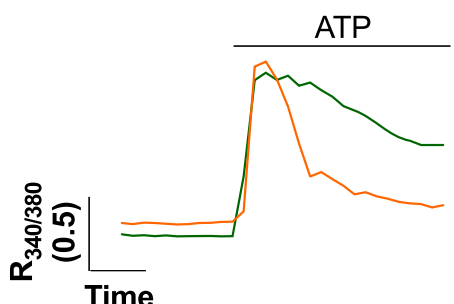

(10s)

e Cytosolic $\mathrm{Ca}^{2+} / \mathrm{FBS} 5 \mathrm{~min}$

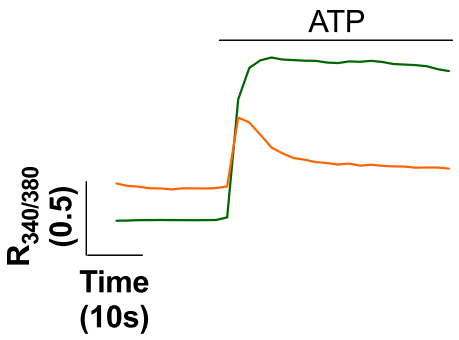

b Cytosolic $\mathrm{Ca}^{2+} /(-)$ Lipoprotein $5 \mathrm{~min}$

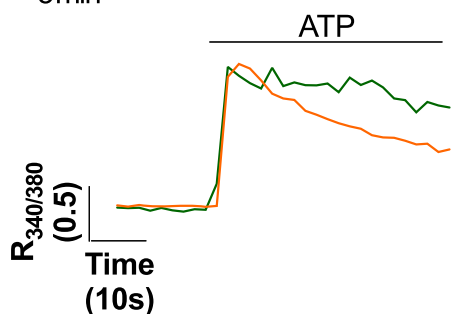

d Cytosolic $\mathrm{Ca}^{2+} / \mathrm{B} 27 \mathrm{ON}$

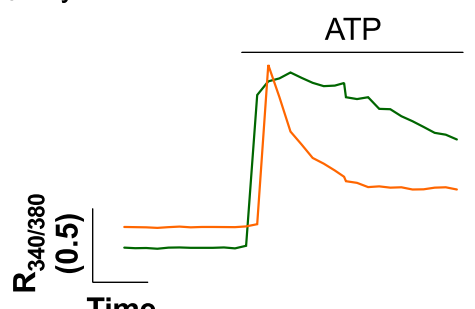

(10s)

f Cytosolic $\mathrm{Ca}^{2+}$ quantification

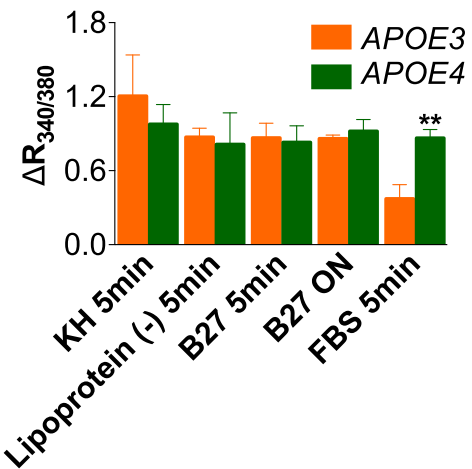

Fig. 6 Loss of modulation of $\mathrm{Ca}^{2+}$ signals by lipids in APOE4 astrocytes. Representative traces of $100 \mu \mathrm{M}$ ATP-induced Ca ${ }^{2+}$ responses in APOE3 and APOE4 immortalized cells in (a) saline medium or Krebs medium (KH) for 2 to 5 min, (b) DMEM medium supplemented with lipoproteindeficient serum (Lipoprotein (-)) for 2 to $5 \mathrm{~min}$, (c) DMEM medium supplemented with B27 for 2 to 5 min, and (d) overnight (ON), and (e) DMEM medium supplemented with $10 \%$ FBS for 5 min. $\mathbf{f}$ Quantification of the ATP-induced intracellular Ca ${ }^{2+}$ peak in cells kept in the different mediums $(N=3)$. Two-way ANOVA was used. $p<0.01\left(^{* *}\right)$ as compared to APOE3 cells kept in the same medium

lipoproteins, such regulation is reversible but stable in $A P O E 3$ astrocytes as long as lipids remain present, and is lost in APOE4 astrocytes.

The absence of lipids potentiates $\mathrm{Ca}^{2+}$ release from the ER and extracellular $\mathrm{Ca}^{2+}$ entry in APOE3 but not APOE4 astrocytes

Since the core of $\mathrm{Ca}^{2+}$-signaling dysregulation in APOE4 astrocytes lies in acidic organelles, is $\mathrm{Ca}^{2+}$ homeostasis in these organelles the target of extracellular lipids in $A P O E 3$ astrocytes? The finding that the increase in ATP-induced $\mathrm{Ca}^{2+}$ signals in APOE3 cells in the absence of lipids/lipoproteins (KH media) was abrogated by Ned-
19, the inhibitor of $\mathrm{Ca}^{2+}$ release from acidic stores (Fig. 7a) might indicate that extracellular lipids decrease $\mathrm{Ca}^{2+}$ levels inside such organelles. Surprisingly, measurement of $\mathrm{Ca}^{2+}$ stored inside acidic organelles using the GPN-elicited depletion showed no increased $\mathrm{Ca}^{2+}$ loading in $A P O E 3$ cells kept in $\mathrm{KH}$ (Fig. 7b) compared to $A P O E 3$ astrocytes kept in the presence of FBS, whereas, as expected, no difference was observed between the two conditions in APOE4 astrocytes (Fig. 7c). An explanation is that, in the absence of extracellular lipids, the release of $\mathrm{Ca}^{2+}$ from lysosomes in APOE3 astrocytes is amplified by the activation of other $\mathrm{Ca}^{2+}$ signaling mechanisms. In fact, the amplification originates in part, from $\mathrm{Ca}^{2+}$ 


\section{a Cytosolic $\mathrm{Ca}^{2+}$}

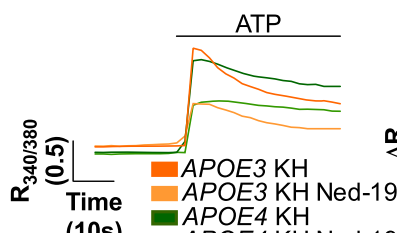

(10s) APOE $4 \mathrm{KH}$ KH Ned-19

C Lysosomal $\mathrm{Ca}^{2+}$ content

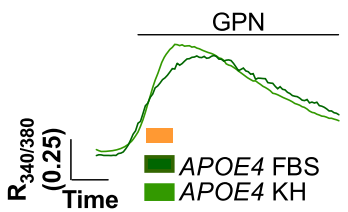

(15s)

e Cytosolic $\mathrm{Ca}^{2+}$
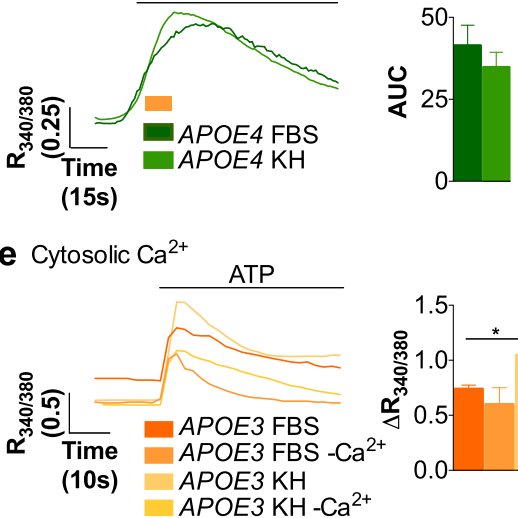

b Lysosomal $\mathrm{Ca}^{2+}$ content

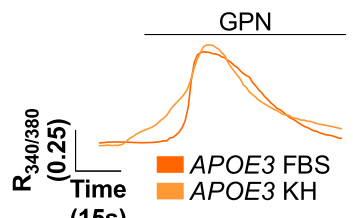

(15s)

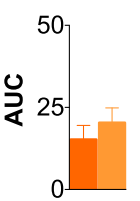

d $\mathrm{ER} \mathrm{Ca}^{2+}$
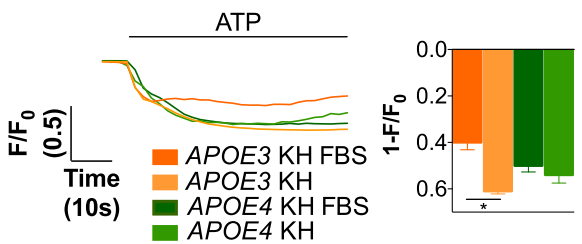

f Cytosolic $\mathrm{Ca}^{2+}$
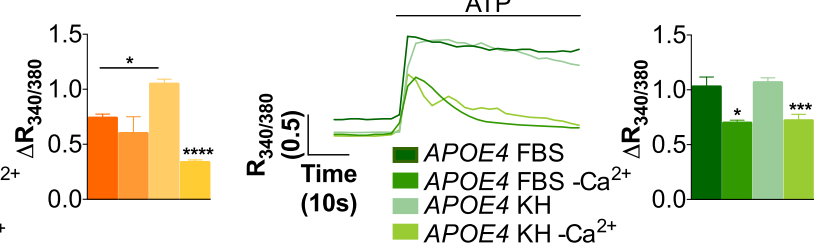

g Lysosomal localization
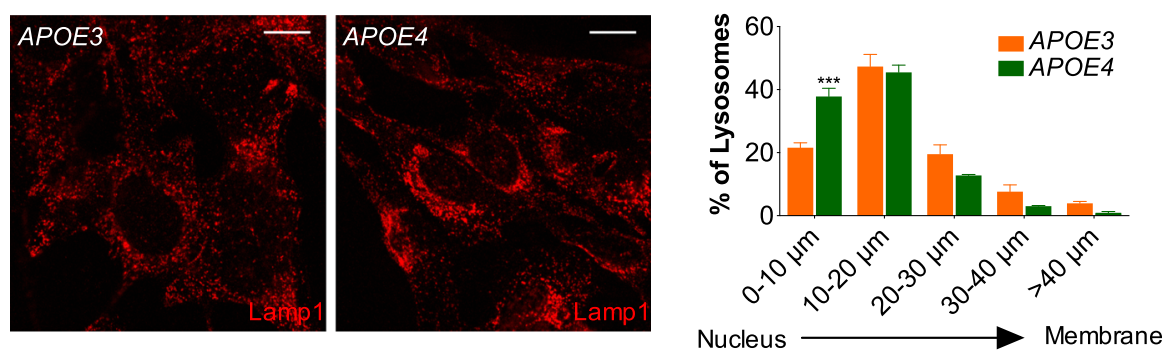

Fig. 7 Loss of lipid-dependent coordination of $\mathrm{Ca}^{2+}$ fluxes across plasma and lysosomal membranes in APOE4 immortalized astrocytes. a Representative traces and quantification of the magnitude of ATP- triggered intracellular $\mathrm{Ca}^{2+}$ responses in cells treated with DMSO or with $100 \mu \mathrm{M}$ Ned 19 for $20 \mathrm{~min}$ in $\mathrm{KH}$ medium $\left(\mathrm{N}=3\right.$ ). b, c Representative traces and quantification of lysosomal $\mathrm{Ca}^{2+}$ content measured as AUC after $200 \mu \mathrm{M}$ GPN addition to (b) APOE3 and (c) APOE4 astrocytes in KH medium, as compared to DMEM medium supplemented with FBS (FBS) (N=3) (FBS-related results were presented in Fig. 3); d Representative traces and quantification of $\mathrm{Ca}^{2+}$ ER release in $100 \mu \mathrm{M}$ ATP-stimulated astrocytes transfected with G-CEPIA1er, and kept in KH medium supplemented or not with FBS $(N=4)$. e, $\mathbf{f}$ Representative traces and quantification of purinergic-induced $\mathrm{Ca}^{2+}$ responses in (e) APOE3 and (f) APOE4 astrocytes in $\mathrm{KH}$ medium supplemented with $10 \%$ of $\mathrm{FBS}$ with or without $\mathrm{Ca}^{2+} / 1$ mM EGTA for $10 \mathrm{~min}$, and $\mathrm{KH}$ medium with $\mathrm{Ca}^{2+}$ or without $\mathrm{Ca}^{2+} / 500 \mu \mathrm{M}$ EGTA for 1 min. g Representative images from Lamp1

immunofluorescence of both cell lines and quantification of the percentage of lysosomes in different ranges of distance, the 0 value being the nucleus in each cell. ( $N=3,30$ to 40 cells quantified). Scale bar represents $15 \mu \mathrm{m}$. One-way ANOVA was used in sections $\mathbf{a}$, $\mathbf{d}$, e and $\mathbf{f}$, unpaired parametric T-test in $\mathbf{b}$ and $\mathbf{c}$, and two-way ANOVA in $\mathbf{g} . p<0.05\left({ }^{*}\right), p<0.001\left(^{* *}\right), p<0.0001\left(^{* * *}\right)$

released from the ER, because the $\mathrm{Ca}^{2+}$ content in the ER was 1.5-fold greater in APOE3 cells kept in $\mathrm{KH}$ than in DMEM/FBS, as recorded with the $\mathrm{Ca}^{2+}$ probe CEPIA1er (Fig. 7d). The same amount of $\mathrm{Ca}^{2+}$ was released from the ER in APOE4 astrocytes kept in the two media, in agreement with the observation that $\mathrm{Ca}^{2+}$ signals are independent of extracellular lipid concentrations in this genotype (Fig. 7d). Another source of $\mathrm{Ca}^{2+}$ is the extracellular $\mathrm{Ca}^{2+}$ entry, because the blockage of extracellular $\mathrm{Ca}^{2+}$ with the cell-impermeable $\mathrm{Ca}^{2+}$ chelator
EGTA greatly reduced (by 3.3 times) ATP-induced $\mathrm{Ca}^{2+}$ responses in $A P O E 3$ astrocytes kept in $\mathrm{KH}$ without lipoproteins, but not in $A P O E 3$ astrocytes kept in $\mathrm{KH}$ with FBS (Fig. 7e). In contrast, EGTA reduced ATP-induced $\mathrm{Ca}^{2+}$ responses in $A P O E 4$ astrocytes to the same extent in the presence or absence of FBS (Fig. 7f). Thus, the data support the idea that extracellular $\mathrm{Ca}^{2+}$ entry is secondary to lysosomal $\mathrm{Ca}^{2+}$ release, and that it is modulated by extracellular lipids in $A P O E 3$ but not in $A P O E 4$ astrocytes. We next sought morphological 
support for this idea by studying the localization of acidic stores inside astrocytes. Again, we resorted to Lamp1 immunostaining to be able to use confocal microscopy. Lysosome distribution was abnormal in APOE4 cells (Fig. 7g); that is, a greater number of Lamp1-positive organelles accumulated near the nucleus in APOE4 astrocytes than in APOE3 astrocytes. Specifically, $37 \%$ of lysosomes are placed at $10 \mu \mathrm{m}$ from the center of the nucleus in APOE4 cells, as compared to $21 \%$ in $A P O E 3$ astrocytes. Plausibly, the altered localization may result in changes in the coupling of such organelles with plasma-membrane channels.

In summary, in $A P O E 3$ astrocytes, activation of extracellular $\mathrm{Ca}^{2+}$ entry secondary to intracellular $\mathrm{Ca}^{2+}$ mobilization underlies the greater $\mathrm{Ca}^{2+}$ responses induced by purinergic receptors in the absence of extracellular lipoproteins. This coordination of signaling pathways does not take place in the presence of lipoproteins, suggesting, again, that lipids have the capacity to change intracellular $\mathrm{Ca}^{2+}$ fluxes in APOE3 astrocytes. By contrast, $A P O E 4$ astrocytes present a higher content of lysosomal $\mathrm{Ca}^{2+}$, but appear to have lost the capacity to have $\mathrm{Ca}^{2+}$ fluxes regulated by lipids.

\section{Lipidomics reveals distinct lipid composition in lysosomal and whole-cell membranes from APOE3 and APOE4 astrocytes}

We posited that lysosomal dysregulation and the refractoriness to lipid-based modulation in APOE4 astrocytes might be caused by altered lipid trafficking and homeostasis due to $A P O E 4$ malfunction-as concluded in a previous section. Since ApoE is a major cholesterol carrier in the brain, we studied cellular cholesterol distribution with filipin staining. We found aberrant intracellular distribution of cholesterol in APOE4 astrocytes, which presented more cholesterol in intracellular clumps, and less in plasma membrane, than APOE3 cells (Fig. 8a). This finding points to impaired cholesterol efflux in APOE4 cells. We also carried untargeted lipidomics because we reasoned that impaired lipid trafficking would leave its mark on astrocyte membranes, such that the profiling of membrane lipids would provide information about lipid dyshomeostasis in APOE4 astrocytes. To determine whether APOE4-mediated changes were specific to lysosomes, we performed lipidomics in lysosomal and whole-membranes of $A P O E 3$ and APOE4 immortalized astrocytes, since, according to a lipid map of the mammalian cell, organelles present distinct lipid compositions [66]. The multivariate analysis PLS-DA revealed that the lipids of lysosomal membranes (Fig. 8b) and whole-membranes (Fig. 8c) clustered independently in $A P O E 3$ and $A P O E 4$ genotypes. The predictive accuracy of the analysis was robust, as the $\mathrm{Q}^{2}$ and $\mathrm{R}_{2} \mathrm{Y}$ scores were 0.616 and 0.986 for lysosome lipidome, and 0.841 and 0.995 for whole-membranes. The PLS-DA analysis thus confirms that $A P O E$ genotype influences membrane lipid composition in astrocytes.

In order to identify which lipids contributed more to the differential group clustering, we used the Variable Importance in the Projection (VIP), such that lipids with VIP $>1$ were the ones with greater weight on the group change. In lysosomal membranes, there were 35 lipids with VIP $>1$ in the APOE4 vs APOE3. ANOVA analysis with a Tukey correction post-test of the intensity (peak values) of these 35 metabolites revealed significant differences due to the $A P O E$ phenotype with a $p$-value < 0.05, confirming, again, that expression of $A P O E 4$ alters the lipidome of lysosomes. We then proceeded to identification of the particular metabolites and calculation of their fold change (FC) in APOE4 vs APOE3 astrocytes. We could identify 19 lipids: 10 phosphatidylcholines (6 increased, 4 decreased), 5 phosphatidylethanolamine (2 increased, 3 decreased), 2 lysophosphatidylcholine (2 decreased), 1 lysophosphatidylethanolamine (decreased), and 1 carnitine (increased) (Fig. 8d). However, multi ttest analysis corrected by a false discovery rate (FDR) of these 19 FC values gave no statistically significant differences (q-value $<0.05)$. This suggests that joint changes in the contents of lipids with VIP $>1$ rather than particular lipids account for the segregation of lipidomes from $A P O E 3$ and $A P O E 4$ lysosomes.

In whole-membranes, 41 metabolites had a VIP $>1$, comparing APOE4 vs APOE3 astrocytes. ANOVA analysis with a Tukey correction post-test of the intensities of these 41 metabolites confirmed significant differences due to the $A P O E$ phenotype with a $p$-value $<0.01$, in agreement with the previous PLS-DA analysis. Twetyone lipids were identified according to their $\mathrm{m} / \mathrm{z}$, and their FC in APOE4 vs APOE3 calculated (Fig. 8e). A multi T-test statistical analysis corrected with FDR, showed that 11 of these metabolites were significantly different (q-value <0.05): 3 lysophosphatidylcholine (1 increased, 2 decreased), 5 phosphatidylcholines (3 increased, 2 decreased), 1 phosphatidylserine (decreased) and 2 carnitines (increased). In short, a general trend is that carnitines and phosphatidylcholines are more abundant in APOE4 astrocytes, whereas APOE3 cells are richer in lysophospholipids.

Overall, this is the first demonstration that the expression of APOE4 changes the lysosomal and cellular lipidomes in astrocytes, supporting a link between altered $\mathrm{Ca}^{2+}$ fluxes and lipid dyshomeostasis. It is worth noting that the different intracellular distribution of cholesterol in APOE3 and APOE4 astrocytes is not due to differences in cholesterol contents between the two genotypes, as the VIP for cholesterol was consistently lower than 1 in the lipidomes (data not shown). 


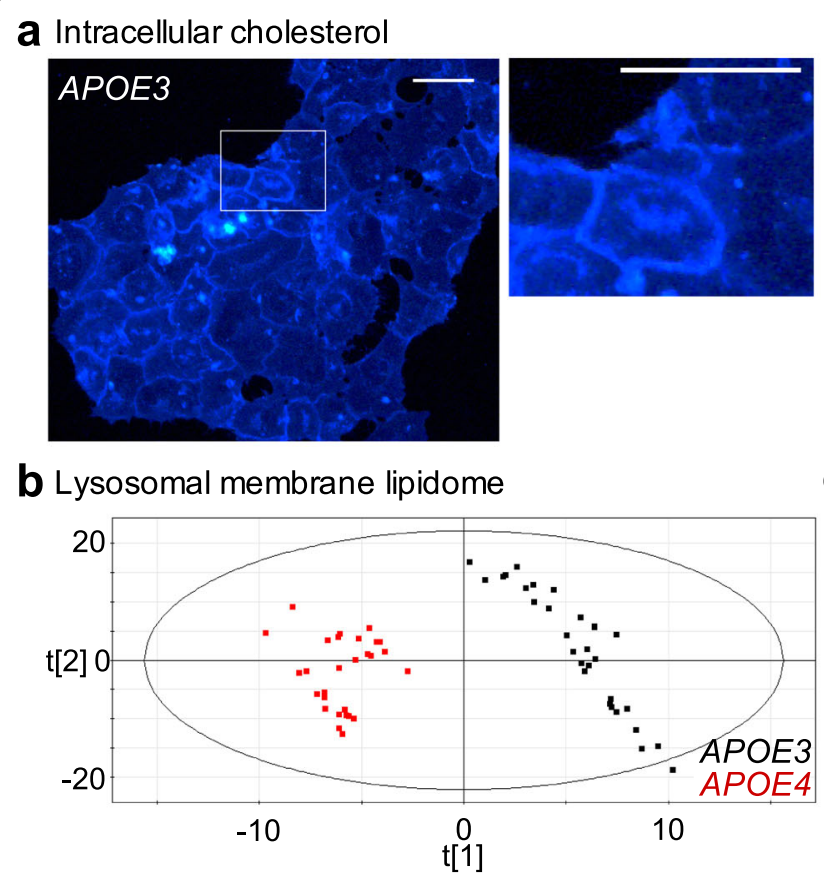

d Identified lipids of lysosomal membrane
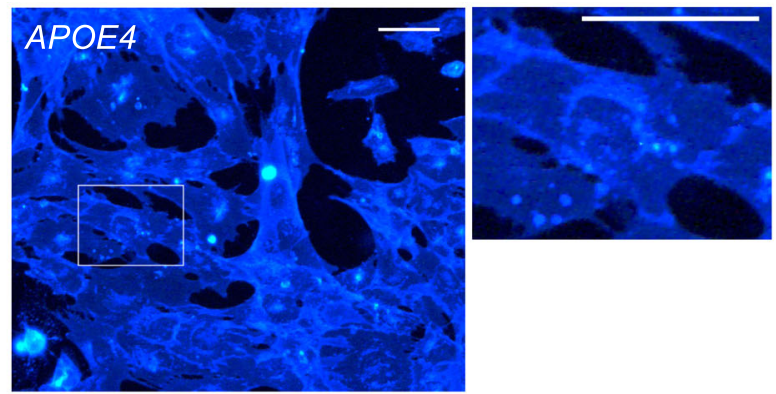

C Whole membrane lipidome

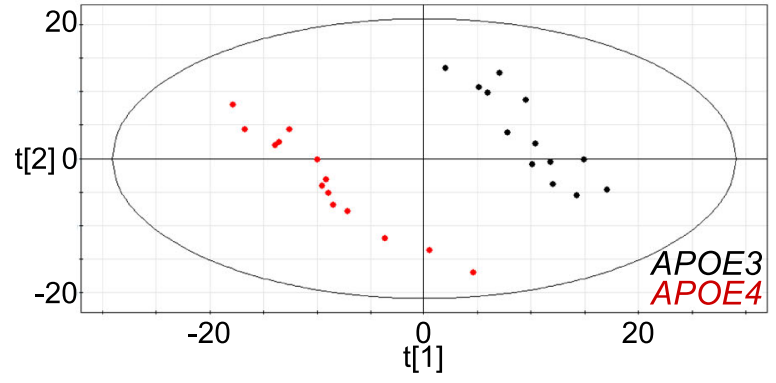

e Identified lipids of whole membrane
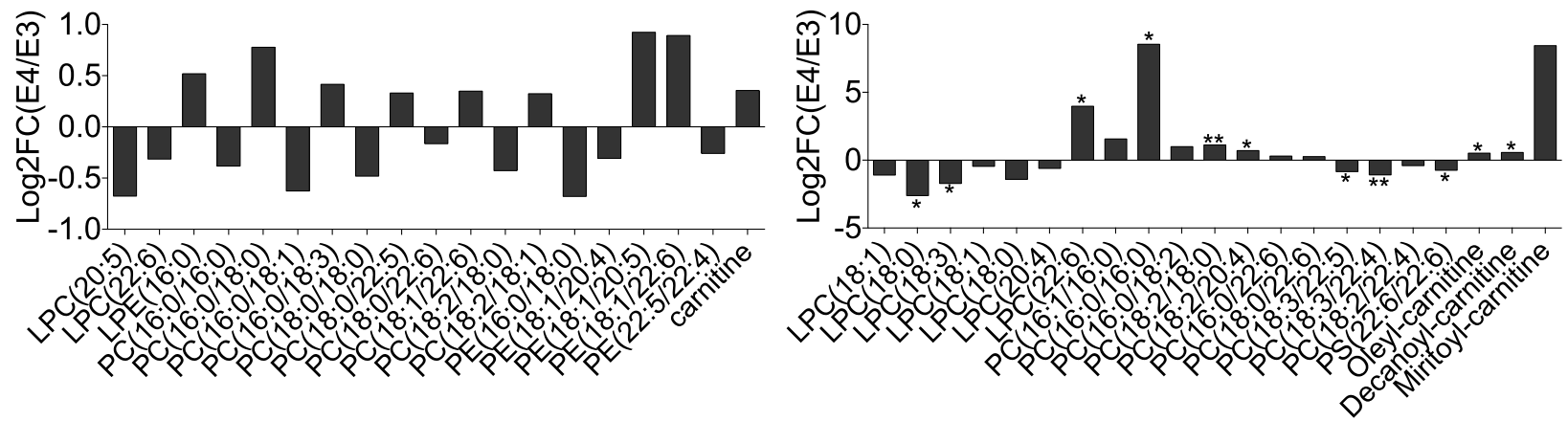

Fig. 8 Different lipid profiles in lysosomal and whole-cell membranes from APOE4 vs APOE3 astrocytes. a Cholesterol accumulation visualized by Filipin III staining in immortalized APOE3 and APOE4 astrocytes $(N=2)$. Scale bar represents $100 \mu \mathrm{m}$. The white squares are amplified in the top right images. b, c PLS-DA analysis of lysosomal (b) and whole-cell membranes (c) from APOE3 and APOE4 immortalized astrocytes. Each dot is an individual sample. $\mathbf{d}$, e Representation of changes of lipids with VIP $>1$ identified in lysosome (d) and whole-cell (e) membranes as logarithm base 2 of fold changes of intensities in APOE4 vS APOE3. Positive values indicate increase and negative values decrease in APOE4 vs APOE3 cells. $q<0.05\left(^{*}\right), q<0.01\left(^{* *}\right)$, multi T-test analysis corrected by false discovery rate (FDR)

\section{Discussion}

The study has two main general findings. First, in immortalized mouse astrocytes expressing human $A P O E 3$ and $A P O E 4$ we found that $A P O E 4$, in comparison to $A P O E 3$, increases receptor-induced $\mathrm{Ca}^{2+}$ responses due to increased release of $\mathrm{Ca}^{2+}$ from acidic organelles, which integrate lysosomes and related organelles. Further, APOE4-expressing astrocytes present distinct lipid profiles and are refractory to $\mathrm{Ca}^{2+}$-signaling regulation by lipids (model in Fig. 9). Second, $\mathrm{Ca}^{2+}$ hyperactivity associated with the APOE4 allele was also found ex vivo in astrocytes from targeted replacement male mice, but not in females, whose astrocytes showed increased $\mathrm{Ca}^{2+}$ responses in $A P O E 3$ mice, matching those in $A P O E 4$ mice. Below we discuss the possible links between dysregulation of $\mathrm{Ca}^{2+}$ signaling, lipid signaling and lipid homeostasis in astrocytes, and the implications in neurodegenerative diseases in which APOE4 is a risk factor in both men and women.

Mechanistically, a key finding is that the $\mathrm{pH}$ of acidic organelles is similar in immortalized APOE4 and APOE3 astrocytes, despite greater expression and activity of the lysosomal $\mathrm{H}^{+}$pump $\mathrm{V}$-ATPase, supporting the idea that the $\mathrm{pH}$ is maintained due to an antiparallel transport of 


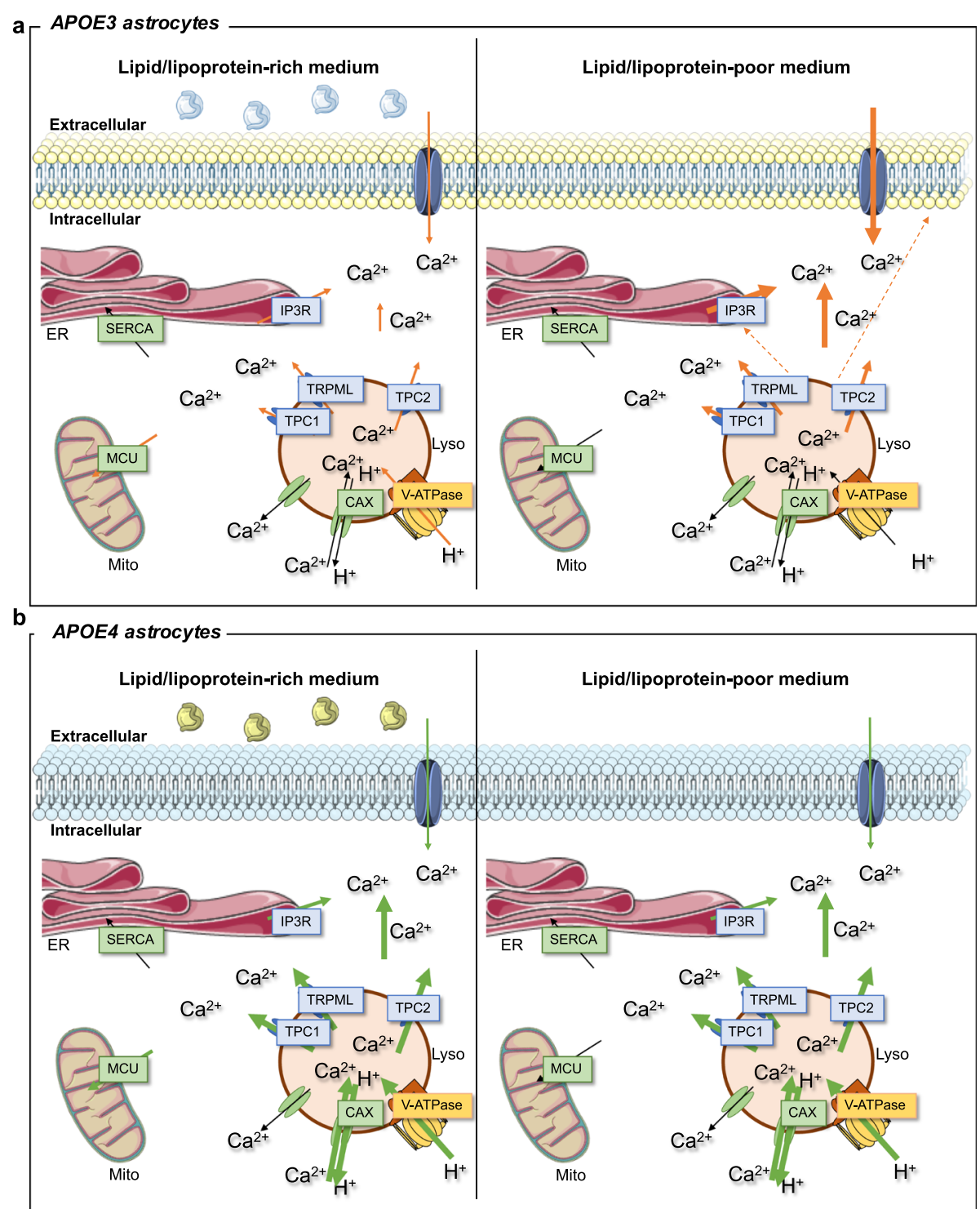

Fig. 9 Summary of the $\mathrm{Ca}^{2+}$ signaling alterations in APOE4 astrocytes. a) $\mathrm{Ca}^{2+}$ signaling pathway of APOE3 (a) and APOE4 (b) astrocytes in the presence (left) or absence (right) of extracellular lipids. The name of channels and receptors that increase cytosolic $\mathrm{Ca}^{2+}$ are in blue rectangles, whereas pathways decreasing cytosolic $\mathrm{Ca}^{2+}$ are in green rectangles. The size of the arrows indicates if the process is increased with respect to APOE3 astrocytes in the presence of extracellular lipids. Plasma-membrane lipids and lipoproteins are shown in different colors in APOE3 and APOE4 astrocytes to reflect their different lipid composition. Organelle and plasmatic membrane graphs were obtained from Smart Servier Medical Art (https://smart.servier.com/)

$\mathrm{H}^{+}$and $\mathrm{Ca}^{2+}$ that extrudes $\mathrm{H}^{+}$and takes up $\mathrm{Ca}^{2+}$ via CAX. Thus, it is plausible that CAX expression and/or activity are increased in $A P O E 4$ astrocytes, too. In consequence, $A P O E 4$ acidic stores have greater $\mathrm{Ca}^{2+}$ content, and hence release more $\mathrm{Ca}^{2+}$ upon purinergic activation. Coordination between intracellular signaling pathways translates the increased $\mathrm{Ca}^{2+}$ mobilization from acidic vesicles to an increased $\mathrm{Ca}^{2+}$ released from ER, and a higher $\mathrm{Ca}^{2+}$ uptake into the mitochondria. In accordance with most studies in the field [36-38, 51, 58-60, 67-69], we considered this heterogeneous population of acidic vesicles as a whole, but we cannot rule out specific differential traits in a particular kind of acidic vesicle. For example, a recent report described differences of $\mathrm{pH}$ between the endolysosomal systems of $A P O E 3$ and APOE4 astrocytes [70], suggesting that greater $\mathrm{pH}$ differences than that detected in our study may exist between genotypes, depending on the compartment analyzed.

It is worth stressing that APOE4 expression not only alters $\mathrm{Ca}^{2+}$ uptake and mobilization from acidic stores, 
but also promotes general dysregulation of these organelles in astrocytes, including higher perinuclear lysosome localization and changes in the overall lysosomal lipidome. The intracellular localization of lysosomes, which is determined by factors such as phospholipids and cholesterol, is linked to many of their functions and pathology [71, 72], although such studies have only been performed in cultured cells, plausibly due to the difficulty of tracking the tortuous intracellular distribution of the endolysosomal system in whole tissues. Specifically, our study confirms the previous observation that aberrant accumulation of cholesterol conditions promotes perinuclear clustering of lysosomes [71]. On the other hand, our results showing aberrant intracellular cholesterol accumulation, together with alterations of phospholipid composition in cellular membranes in APOE4 astrocytes, point to dysregulation of the formation, internalization, and degradation of lipoproteins, processes in which lysosomes and related acidic vesicles participate [73]. Moreover, alterations of cholesterol trafficking and intracellular cholesterol accumulation have been linked to impaired autophagy [74]. Accordingly, impaired autophagy [75] and reduced lysosomedependent amyloid degradation [76] have been reported in immortalized $A P O E 4$ astrocytes, and in astrocytes derived from APOE4 iPSC, respectively. Transcriptome analyses of whole brains of aged APOE4 targeted replacement mice also revealed dysregulated expression of genes related to the endolysosomal system, although the contributions of the different cellular types were not studied [77]. Dysregulation of $\mathrm{Ca}^{2+}$ homeostasis might be a cause rather than a consequence of lysosomal dysfunction, as there is evidence supporting $\mathrm{Ca}^{2+}$ release from acidic stores controlling endolysosomal trafficking and autophagy [67, 78]. Moreover, in astrocytes, it has been reported that NAADP-induced $\mathrm{Ca}^{2+}$ release from lysosome-like organelles increases autophagic markers [79], and inhibits the fusion of the autophagosome with lysosomes, thus arresting the autophagic fluxes [69].

An unexpected discovery of this study is that lipoproteins modulate the magnitude of ATP-induced cytosolic $\mathrm{Ca}^{2+}$ responses in $A P O E 3$ astrocytes by changing the interplay of $\mathrm{Ca}^{2+}$ signaling and fluxes among organelles and the plasma membrane. The observation that the down-regulation of purinergic-induced $\mathrm{Ca}^{2+}$ responses in the presence of lipids is quick and reversible rules out the implication of gene expression and down-regulation of purinergic receptors. Rather, the phenomenon supports the emerging notion of lipid-mediated control of $\mathrm{Ca}^{2+}$ channels. Precedents are the activation by lysophosphatidylcholine of astrocytic extracellular $\mathrm{Ca}^{2+}$ entry [80], and the regulation by lipids of some of the channels responsible for SOCE. Specifically, cholesterol regulates TRPC1 in neutrophils [81] and STIM in pulmonary endothelial cells [82], whereas phosphoinositides regulate TRPC3,6,7 channels in numerous cell types [83]. Recently, very-low-density lipoproteins have been shown to inhibit STIM in atrial myocytes [84]; this study and ours are the first to report lipoproteins regulating $\mathrm{Ca}^{2+}$ signaling. It is worth stressing that the all-or-nothing experimental design consisting in testing the effects of media with and without lipoproteins allowed us to obtain proof of concept that lipoproteins modulate $\mathrm{Ca}^{2+}$ excitability in astrocytes, but in physiological settings, $\mathrm{Ca}^{2+}$ signaling in astrocytes is, plausibly, modulated by subtle changes in brain lipid contents.

Importantly, lipoprotein-mediated regulation of purinergic $\mathrm{Ca}^{2+}$ signaling is lost in APOE4 astrocytes. Several factors could explain this finding. First, the accumulation of lysosomes around the nucleus may uncouple the lysosomal $\mathrm{Ca}^{2+}$ release and SOCE. Second, the entry of extracellular $\mathrm{Ca}^{2+}$ triggered by low levels of $\mathrm{Ca}^{2+}$ inside acidic vesicles requires the TPC2 channels of acidic vesicles, which are less expressed in APOE4 than in APOE3 astrocytes. Third, $\mathrm{Ca}^{2+}$ inside the acidic stores is higher in APOE4 astrocytes compared to APOE3 cells; hence SOCE mechanisms may not be triggered after purinergic-induced lysosomal $\mathrm{Ca}^{2+}$ release. Fourth, $A P O E 4$ astrocytes may be devoid of the right concentration of lipids to modulate lysosomal and $\mathrm{Ca}^{2+}$ entry channels, as they have different lysosomal and cellular lipidomes compared to APOE3 cells. Specifically, the decreased contents of lysophosphatidylcholine species in $A P O E 4$ vs $A P O E 3$ cellular membranes may explain the uncoupling of $\mathrm{Ca}^{2+}$ fluxes in $A P O E 4$ astrocytes, for these lipids activate SOCE [80], and the cation TRPV2 channel [85] in astrocytes. Moreover, the increase in phosphatidylcholines in APOE4 lysosomes is consistent with the observed potentiation of NAADP-mediated $\mathrm{Ca}^{2+}$ release, since, as noted, phosphatidylcholines stimulate this pathway [65]. Finally, the decrease in plasma membrane cholesterol in APOE4 astrocytes compared to APOE3 cells may underlie the reduced SOCE activation, because SOCE requires cholesterol in different cell types [81, 82, 86]. Cholesterol alterations have been also reported in human APOE4-iPSC derived astrocytes [76], and in brains from 12-month-old APOE4 mice [87]. Interestingly, cholesterol synthesis is decreased in astrocytes upon aging [88], which might exacerbate APOE4-elicited lipid dyshomeostasis and $\mathrm{Ca}^{2+}$ signaling.

Remarkably, the differences in $\mathrm{Ca}^{2+}$ signaling between $A P O E 4$ and $A P O E 3$ astrocytes were also detected ex vivo in 9-12-week-old male but not in female mice, suggesting that the $A P O E$ allele affects astrocyte excitability in a sexdependent manner. The present study thus adds to the increasing evidence of complex interactions between $A P O E$ genotype and sex, as shown, for example, in lipid-related metabolic variations [89], cerebrovascular pathology [90], 
and tau levels in the cerebrospinal fluid [91]. The following scenarios might explain the sex bias in astrocyte excitability in different $A P O E$ alleles. First, $\mathrm{Ca}^{2+}$ signals in female astrocytes might be by default higher, regardless of the $A P O E$ allele. Along these lines, a recent study showed greater estradiol-induced $\mathrm{Ca}^{2+}$ signals in astrocytes from female mice than from male astrocytes [92]. Second, the down-regulation of $\mathrm{Ca}^{2+}$-based excitability by lipids observed in immortalized $A P O E 3$ astrocytes might not occur in females. Note that ex-vivo $\mathrm{Ca}^{2+}$ responses in female mice resemble $\mathrm{Ca}^{2+}$ responses in immortalized astrocytes in the absence of lipoproteins. Emerging evidence indeed points to a distinct impact of $A P O E$ genotype on brain lipid metabolism [76, 87] with a sex bias [93]. In the latter study, lipid clustering by principal component analysis of cortical lipidomes unravels sample segregation by sex in APOE3 but not in APOE4 16 month-old mice [93]. That is, sex differences were observed in $A P O E 3$ but not in APOE4 mice, as in our study. Specifically, there was a trend for greater concentrations of phosphatidylcholines and lysophosphatidylcholines in APOE3 male than in APOE3 female mice [93]. Taking together these and our results, it is plausible that the interplay of sex, $A P O E$ genotype and age differently shapes the composition of lipid milieus in male and females through life, resulting in distinct astrocytic $\mathrm{Ca}^{2+}$ responses.

Whatever the case, our study supports that immortalized astrocytes from human $A P O E$ replacement mice may be a model to understand APOE4 pathology in males. The fact that $\mathrm{Ca}^{2+}$-based astrocyte excitability controls neural functions [94] lends credence to the hypothesis that APOE4-elicited dysregulation of $\mathrm{Ca}^{2+}$ fluxes in astrocytes contributes to the impairment of brain activity and metabolism in the healthy brain, as repeatedly reported in humans [4-6, 8], although, of note, no sex-based stratification existed in these studies. It is worth noting that the differences in $A P O E$ genotype were observed in 10-week old male mice, pointing to early detrimental actions of APOE4 in brain, not surprisingly so, for $A P O E$ alleles are acquired at conception. This is important because, although metabolic alterations and distinct patterns of brain activity have been reported in young humans harboring APOE4 [95, 96], and olfactory-memory impairment exists in 6 month-old APOE4 mice [13, 89], most studies with human APOE4 gene targeted replacement of murine $A P O E$ have been conducted with aged mice, and occasionally, middleaged (over 10 months) rodents [97].

We emphasize that the APOE4 phenotype observed in the aforementioned studies, as well as in our study, occurs in the absence of LOAD pathology, although it may render brains more vulnerable to age-dependent ailments. Thus, a wealth of data suggests that APOE4 exacerbates the impairment of $A \beta$ processing and clearance caused by ApoE, leading to increased accumulation, and hence aggregation, of $A \beta$ in the brain [70]. In addition, ApoE4 has recently been reported to potentiate Tau-mediated neurodegeneration independently of $A \beta$ [24]. However, it is increasingly more recognized that alterations in lysosomal functions [98], lipid homeostasis [99], and $\mathrm{Ca}^{2+}$ signaling play a role in LOAD, too. The $\mathrm{Ca}^{2+}$ hypothesis in LOAD contends that aberrant $\mathrm{Ca}^{2+}$ responses in neurons associated with $\mathrm{A} \beta$, Tau, and the glutamatergic system underlie cognitive impairment [100]. In addition, $\mathrm{Ca}^{2+}$ signaling is profoundly dysregulated in astrocytes in animal models of $\operatorname{AD}[39,101]$, mainly due to aberrant activation of purinergic receptors [56]. Our results support the notion that APOE4 may exacerbate the dysregulation of $\mathrm{Ca}^{2+}$ signaling in male astrocytes in LOAD owing to lysosomal dysfunction caused by lipid dyshomeostasis. Dysregulation of astrocyte excitability in LOAD may, in turn, contribute to neural-circuit hyperactivity independently of $A \beta$ and Tau pathologies [102], supporting astrocytic-lysosome targeted therapies in LOAD, at least in male patients.

An outstanding question in APOE4-targeted therapeutics is whether the mutated domain renders ApoE4 toxic, or less efficient, than ApoE3 and ApoE2. Alternatively, since ApoE is lower in cerebrospinal fluid (CSF) of APOE4 individuals [62], and in plasma, CSF, and brain tissue of $A P O E 3$ and $A P O E 4$ as compared with $A P O E 2$ targeted replacement mice [103], is it the problem that ApoE4 is less abundant? The answers to these questions are important because they will determine whether therapeutic strategies should be aimed to increase or decrease ApoE production, or to replace $A P O E 4$ with $A P O E 3$ or APOE2. It seems unlikely that the effects of $A P O E 4$ on lysosomal-related $\mathrm{Ca}^{2+}$ fluxes are due to decreased expression of APOE4, because $A P O E 4$ over-expression did not revert $\mathrm{Ca}^{2+}$ responses to the levels observed in APOE3 cells. It is also unlikely that the $A P O E 4$ phenotypes are caused by direct interaction between ApoE4 and V-ATPase and/or NAADP receptors in the acidic organelles, as shown for APOD, another brain apolipoprotein that participates in vesiclemediated astrocyte-to-neuron communication [104] and prevents lysosomal membrane permeabilization [51], given that our immunocytochemistry showed scarce ApoE in astrocytic lysosomes. Rather, the data support malfunction of ApoE4, which could be rescued by overexpression of $A P O E 3$, as shown here, and perhaps $A P O E 2$ [50]. Whether drugs designed to increase ApoE4 lipidation in order to enhance the capacity of the lipoprotein to carry cholesterol [105] would restore intracellular lipid dyshomeostasis in astrocytes is an open question, since the mechanisms whereby the $A P O E$ allele modifies lipid contents and distribution in astrocyte membranes remain to be explored. Alternatively, 
because APOE4 exacerbates ApoE-mediated A $\beta$ aggregation [70] and Tau pathology [24], ApoE removal is being pursued by immunotherapy [106]. However, considering the pleiotropic functions of $A P O E$ as a lipid carrier between cells, and plausibly inside cells, chronic removal of ApoE may have secondary effects. All in all, development of APOE4-specific therapeutics is in order. To this end, better understanding of the basic biology of $A P O E$, and of the particulars of APOE4 action and sex bias independently of $A \beta$ and Tau, are necessary. Overall, our findings that $A P O E 4$ per se disrupts the lipid-based regulation of $\mathrm{Ca}^{+2}$ fluxes in astrocytes due to lysosomal dysregulation supports the notion that astrocyte dysfunction contributes to APOE4 pathology in neurodegeneration.

\section{Conclusions}

Taking together ex vivo and in vitro data, we conclude that APOE4 malfunction augments $\mathrm{Ca}^{2+}$-based excitability in astrocytes due to dysregulation of calcium fluxes in and out the lysosome, associated with lipid dyshomeostasis, and that the phenomenon might be maleassociated. One implication of the study is that it supports the use of therapies aimed to restoring lysosomal dysfunction in astrocytes, including targeted overexpression of APOE3 or APOE2, in order to halt the accelerated progression of LOAD in male APOE4 carriers. Since $\mathrm{Ca}^{2+}$ signaling is central to the regulation of neural circuits by astrocytes, another implication of the study is that the therapeutic correction of astrocyte excitability might reverse the neural-circuit hyperactivity observed in APOE4-harboring humans and mice in the absence of $A \beta$ and Tau pathologies. Finally, clarifying the sex bias in the efficacy of APOE4 targeted therapeutics is a must, for the mechanisms underlying APOE4 pathology might differ in males and females.

\footnotetext{
Abbreviations

APOE: Apolipoprotein E; ACSF: Artificial cerebrospinal fluid medium; AUC: Area under the curve; CAX: $\mathrm{Ca} 2+/ \mathrm{H}+$ exchanger; CSF: Cerebrospinal fluid; ER: Endoplasmic reticulum; FBS: Fetal bovine serum; FC: Fold change; GECl: Genetically encoded $\mathrm{Ca}^{2+}$ indicators; GPN: Glycyl-L-phenylalanine 2naphthylamide; h: Hours; IP3: Inositol 1,4,5-triphosphate; KH: Krebs medium; Lipo: Lipofectamine; LOAD: Late-onset Alzheimer's disease;

LPC: Lysophosphatidylcholine; LPE: Lysophosphatidylethanolamine; LTP: Long-term potentiation; min: Minutes; NAADP: Nicotinic acid adenine dinucleotide phosphate; NMDG: N-methyl-D-glucamine; PC: Phosphatidylcholine; PE: Phosphatidylethanolamine;

PS: Phosphatidylserine; ROI: Region of interest; s: Seconds; Sc: Scramble; SOCE: Store-operated $\mathrm{Ca}^{2+}$ entry; SR101: Sulforhodamine; Tpc1: Two-pore channels 1; Tpc2: Two-pore channels 2; Trpml: Transient receptor potential mucolipin; TTX: Tetrodotoxin; VIP: Variable importance in projection; Vs: Versus
}

\section{Acknowledgements}

We thank Dr. David M. Holtzman for providing us with APOE3 and APOE4 immortalized astrocytes.

\section{Authors' contributions}

RL-A performed calcium imaging experiments in immortalized astrocytes, participated in the rest of in vitro experiments, analyzed data and participated in the writing of the manuscript. CG-A and GP performed experiments ex vivo. RP-M and MDG performed $\mathrm{pH}$ measurements. MM- $\mathrm{V}$ and $\mathrm{MV}$ isolated lysosomes. Lipidomics were done by TG-B, JLG and JV. AG participated in the immunocytochemistry experiments and discussions about lysosomal dysfunction. EH and EK produced and provided the GFP-APOE vectors. EG contributed to the conception of the project, the discussion of results and the writing and revising of the article. RM conceived, designed and supervised the project, performed some calcium imaging experiments, analyzed data and was responsible for data interpretation and writing and revising the manuscript. All authors read and approved the final manuscript.

\section{Funding}

This research was mainly funded by grants TV3-20141430, TV3-20141432 and TV3-20141431 from La Marató de Televisió de Catalunya (TV3) to EG, AG and JV respectively, and grants 2107 SGR1780 from AGAUR (Generalitat de Catalunya) to RM, 2017 SGR547 from AGAUR (Generalitat de Catalunya) to EG, BFU2016-75107-P from Ministerio de Economia, Industria y Competividad (Spanish Government) to GP, BFU2015-68149-R from Ministerio de Ciencia e Innovación (Spanish Government) and co-financed by European Regional Development Fund to MDG and PI18/01557 from Instituto de Salud Carlos III (ISCiii, Spanish Government) co-financed by FEDER funds from European Union to AG. CG-A was awarded a PhD fellowship BES-2017-080303 from Ministerio de Economía, Industria y Competividad (Spanish Government).

\section{Availability of data and materials \\ Not applicable.}

\section{Ethics approval}

All experimental procedures were according to the animal research regulations (RD53/2013 and 2010/63/UE) from Spain and European Union, and with the approval of the Committees of Animal Research from the Institutional Animal Ethics Committee of CSIC.

\section{Consent for publication}

Not applicable.

\section{Competing interests}

The authors declare that they have no competing interests.

\section{Author details}

${ }^{1}$ Unitat de Bioquímica de Medicina, Departament de Bioquímica i Biologia Molecular, and, Institut de Neurociències (INc), Facultat de Medicina, Universitat Autònoma de Barcelona, 08193 Cerdanyola del Vallès, Barcelona, Catalonia, Spain. ${ }^{2}$ Cajal Institute, Consejo Superior de Investigaciones Científicas (CSIC), 28002 Madrid, Spain. ${ }^{3}$ Departamento de Biología Celular, Genética y Fisiología, Facultad de Ciencias, Instituto de Investigación Biomedica de Málaga (IBIMA), Universidad de Málaga, 29071 Málaga, Spain. ${ }^{4}$ Centro de Investigación Biomédica en Red sobre Enfermedades Neurodegenerativas (CIBERNED), 28031 Madrid, Spain. ${ }^{5}$ Departamento de Bioquímica y Biología Molecular, Facultad de Farmacia, Universidad de Sevilla, Instituto de Biomedicina de Sevilla (IBiS)-Hospital Universitario Virgen del Rocío/CSIC/Universidad de Sevilla, 41012 Sevilla, Spain. ${ }^{6}$ Departamento de Química, Facultad de Ciencias Experimentales, Campus de El Carmen, Centro de Investigación en Recursos Naturales, Salud y Medio Ambiente (RENSMA), Universidad de Huelva, 21007 Huelva, Spain. ${ }^{7}$ Departamento de Bioquímica y Biología Molecular y Fisiología, Instituto de Biología y Genética Molecular, Universidad de Valladolid-CSIC, 43007 Valladolid, Spain.

${ }^{8}$ Alzheimer's Disease Research Laboratory, MassGeneral Institute for Neurodegenerative Disease, Massachusetts General Hospital, Harvard Medical School, Charlestown, MA 02129, USA. ${ }^{9}$ Present Address: Institute of Neuropathology, University Hospital of Zurich, 8091 Zurich, Switzerland. ${ }^{10}$ Neurodegenerative Diseases Research Group, Vall d'Hebron Research Institute (VHIR), 08035 Barcelona, Spain. ${ }^{11}$ ICREA, Passeig Lluís Companys 23, 08010 Barcelona, Catalonia, Spain. 
Received: 7 August 2019 Accepted: 25 May 2020

Published online: 09 June 2020

\section{References}

1. Marais AD. Apolipoprotein $\mathrm{E}$ in lipoprotein metabolism, health and cardiovascular disease. Pathology. 2019;51:165-76.

2. Zhao N, Liu C-C, Qiao W, et al. Apolipoprotein E, receptors, and modulation of Alzheimer's disease. Biol Psychiatry. 2018;83:347-57.

3. Liu CC, Liu CC, Kanekiyo T, et al. Apolipoprotein E and Alzheimer disease: risk, mechanisms and therapy. Nat Rev Neurol. 2013;9:106-18.

4. Caselli RJ, Reiman EM, Osborne D, et al. Longitudinal changes in cognition and behavior in asymptomatic carriers of the APOE e4 allele. Neurology. 2004:62:1990-5.

5. Stevens BW, DiBattista AM, William Rebeck G, et al. A gene-brain-cognition pathway for the effect of an Alzheimer's risk gene on working memory in young adults. Neuropsychologia. 2014;61:143-9.

6. Kunz L, Schröder TN, Lee H, et al. Reduced grid-cell-like representations in adults at genetic risk for Alzheimer's disease. Science. 2015;350:430-3.

7. Ji Y, Gong Y, Gan W, et al. Apolipoprotein E isoform-specific regulation of dendritic spine morphology in apolipoprotein $E$ transgenic mice and Alzheimer's disease patients. Neuroscience. 2003;122:305-15.

8. Reiman EM, Chen K, Alexander GE, et al. From the cover: correlations between apolipoprotein E 4 gene dose and brain-imaging measurements of regional hypometabolism. Proc Natl Acad Sci. 2005;102:8299-302.

9. Rodriguez GA, Burns MP, Weeber EJ, et al. Young APOE4 targeted replacement mice exhibit poor spatial learning and memory, with reduced dendritic spine density in the medial entorhinal cortex. Learn Mem. 2013;20:256-66.

10. Klein RC, Acheson SK, Mace BE, et al. Altered neurotransmission in the lateral amygdala in aged human apoE4 targeted replacement mice. Neurobiol Aging. 2014;35:2046-52.

11. Wang C, Wilson WA, Moore SD, et al. Human apoE4-targeted replacement mice display synaptic deficits in the absence of neuropathology. Neurobiol Dis. 2005;18:390-8.

12. Najm R, Jones EA, Huang Y. Apolipoprotein E4, inhibitory network dysfunction, and Alzheimer's disease. Mol Neurodegener. 2019;14:24

13. Peng KY, Mathews PM, Levy E, et al. Apolipoprotein E4 causes early olfactory network abnormalities and short-term olfactory memory impairments. Neuroscience. 2017;343:364-71.

14. Bertram L, McQueen MB, Mullin K, et al. Systematic meta-analyses of Alzheimer disease genetic association studies: the AlzGene database. Nat Genet. 2007:39:17-23.

15. Yamazaki Y, Painter MM, Bu G, et al. Apolipoprotein E as a therapeutic target in Alzheimer's disease: a review of basic research and clinical evidence. CNS Drugs. 2016;30:773-89.

16. Neu SC, Pa J, Kukull W, et al. Apolipoprotein E genotype and sex risk factors for Alzheimer disease: a meta-analysis. JAMA Neurol. 2017;74:1178-89.

17. Riedel BC, Thompson PM, Brinton RD. Age, APOE and sex: triad of risk of Alzheimer's disease. J Steroid Biochem Mol Biol. 2016;160:134-47.

18. Rasmussen KL, Tybjærg-Hansen A, Nordestgaard BG, et al. Absolute 10-year risk of dementia by age, sex and APOE genotype: a population-based cohort study. CMAJ. 2018;190:E1033-41.

19. Agosta F, Vossel KA, Miller BL, et al. Apolipoprotein E $\varepsilon 4$ is associated with disease-specific effects on brain atrophy in Alzheimer's disease and frontotemporal dementia. Proc Natl Acad Sci. 2009;106:2018-22.

20. Baum L, Lam LCW, Kwok T, et al. Apolipoprotein E epsilon4 allele is associated with vascular dementia. Dement Geriatr Cogn Disord. 2006:22:301-5.

21. Cao J, El Gaamouch F, Meabon JS, et al. ApoE4-associated phospholipid dysregulation contributes to development of tau hyper-phosphorylation after traumatic brain injury. Sci Rep. 2017;7:1-12.

22. Xu Q, Bernardo A, Walker D, et al. Profile and regulation of apolipoprotein $\mathrm{E}$ (ApoE) expression in the CNS in mice with targeting of green fluorescent protein gene to the ApoE locus. J Neurosci. 2006;26:4985-94.

23. Parhizkar S, Arzberger T, Brendel M, et al. Loss of TREM2 function increases amyloid seeding but reduces plaque-associated ApoE. Nat Neurosci. 2019;22: 191-204.

24. Shi Y, Yamada K, Liddelow SA, et al. ApoE4 markedly exacerbates tau-mediated neurodegeneration in a mouse model of tauopathy. Nature. 2017:549:523-7.

25. Holtzman DM, Herz J, Bu G. Apolipoprotein E and apolipoprotein E receptors: Normal biology and roles in Alzheimer disease. Cold Spring Harb Perspect Med. 2012;2:a006312.
26. Kastanenka KV, Moreno-Bote R, De Pittà M, et al. A roadmap to integrate astrocytes into Systems Neuroscience. Glia. 2019;68:23632.

27. Mauch DH, Nägier K, Schumacher S, et al. CNS synaptogenesis promoted by glia-derived cholesterol. Science. 2001;294:1354-7.

28. Petrov AM, Kasimov MR, Zefirov AL. Brain cholesterol metabolism and its defects: linkage to neurodegenerative diseases and synaptic dysfunction. Acta Nat. 2016;8:58-73.

29. Perea $G$, Araque A. Astrocytes potentiate transmitter release at single hippocampal synapses. Science. 2007:317:1083-6.

30. Henneberger C, Papouin T, Oliet SHR, et al. Long-term potentiation depends on release of d-serine from astrocytes. Nature. 2010;463:232-6.

31. Lee HS, Ghetti A, Pinto-Duarte A, et al. Astrocytes contribute to gamma oscillations and recognition memory. Proc Natl Acad Sci. 2014;111:E3343-52.

32. Marpegan L, Swanstrom AE, Chung K, et al. Circadian regulation of ATP release in astrocytes. J Neurosci. 2011:31:8342-50.

33. Araque A, Carmignoto G, Haydon PG, et al. Gliotransmitters travel in time and space. Neuron. 2014:81:728-39.

34. Zorec R, Araque A, Carmignoto G, et al. Astroglial excitability and Gliotransmission: an appraisal of Ca 2+ as a Signalling route. ASN Neuro. 2012;4: AN20110061.

35. Rusakov DA. Disentangling calcium-driven astrocyte physiology. Nat Rev Neurosci. 2015;16:226-33.

36. Raffaello A, Mammucari C, Gherardi G, et al. Calcium at the Center of Cell Signaling: interplay between endoplasmic reticulum, mitochondria, and lysosomes. Trends Biochem Sci. 2016;41:1035-49.

37. Barceló-Torns M, Lewis AM, Gubern A, et al. NAADP mediates ATP-induced Ca2+ signals in astrocytes. FEBS Lett. 2011;585:2300-6.

38. Eraso-Pichot A, Larramona-Arcas R, Vicario-Orri E, et al. CREB decreases astrocytic excitability by modifying subcellular calcium fluxes via the sigma1 receptor. Cell Mol Life Sci. 2017:74:937-50.

39. Kuchibhotla KV, Lattarulo CR, Hyman BT, et al. Synchronous hyperactivity and intercellular calcium waves in astrocytes in Alzheimer mice. Science. 2009:323: $1211-5$

40. Tambini MD, Pera M, Kanter E, et al. ApoE 4 upregulates the activity of mitochondria- associated ER membranes. EMBO Rep. 2015;17:1-10.

41. Sunshine H, Iruela-Arispe ML. Membrane lipids and cell signaling. Curr Opin Lipidol. 2017;28:408-13.

42. Knouff $\mathrm{C}$, Hinsdale ME, Mezdour $\mathrm{H}$, et al. Apo E structure determines VLDL clearance and atherosclerosis risk in mice. J Clin Invest. 1999;103:1579-86.

43. Sullivan PM, Mezdour $\mathrm{H}$, Aratani $Y$, et al. Targeted replacement of the mouse Apolipoprotein E gene with the common human APOE3 allele enhances diet-induced hypercholesterolemia and atherosclerosis. J Biol Chem. 1997;272:17972-80

44. Morikawa M, Fryer JD, Sullivan PM, et al. Production and characterization of astrocyte-derived human apolipoprotein E isoforms from immortalized astrocytes and their interactions with amyloid- $\beta$. Neurobiol Dis. 2005;19:66-76.

45. Ting JT, Daigle $T L$, Chen $Q$, et al. Acute brain slice methods for adult and aging animals: application of targeted patch clamp analysis and optogenetics; 2014. p. 221-42

46. Kafitz KW, Meier SD, Stephan J, et al. Developmental profile and properties of sulforhodamine 101-labeled glial cells in acute brain slices of rat hippocampus. J Neurosci Methods. 2008;169:84-92.

47. Martin R, Bajo-Graneras R, Moratalla R, et al. Circuit-specific signaling in astrocyte-neuron networks in basal ganglia pathways. Science. 2015;349:730-4.

48. Nimmerjahn A, Kirchhoff F, Kerr JND, et al. Sulforhodamine 101 as a specific marker of astroglia in the neocortex in vivo. Nat Methods. 2004; 1:31-7.

49. Suzuki J, Kanemaru K, Ishii K, et al. Imaging intraorganellar Ca2+ at subcellular resolution using CEPIA. Nat Commun. 2014;5:4153.

50. Hudry E, Dashkoff J, Roe AD, et al. Gene transfer of human Apoe isoforms results in differential modulation of amyloid deposition and neurotoxicity in mouse brain. Sci Transl Med. 2013:5:212ra161.

51. Pascua-Maestro R, Diez-Hermano S, Lillo C, et al. Protecting cells by protecting their vulnerable lysosomes: identification of a new mechanism for preserving lysosomal functional integrity upon oxidative stress. PLoS Genet. 2017:13:1-33.

52. Storrie B, Amadden E. Isolation of subcellular organelles; 1990. p. 203-25.

53. González-Domínguez R, García-Barrera T, Gómez-Ariza JL. Metabolomic study of lipids in serum for biomarker discovery in Alzheimer's disease using direct infusion mass spectrometry. J Pharm Biomed Anal. 2014;98:321-6. 
54. Vandesompele J, De Preter K, Pattyn F, et al. Accurate normalization of realtime quantitative RT-PCR data by geometric averaging of multiple internal control genes. Genome Biol. 2002;3:RESEARCH0034.

55. Khakh BS, Sofroniew MV. Diversity of astrocyte functions and phenotypes in neural circuits. Nat Neurosci. 2015;18:942-52.

56. Delekate A, Füchtemeier M, Schumacher T, et al. Metabotropic P2Y1 receptor signalling mediates astrocytic hyperactivity in vivo in an Alzheimer's disease mouse model. Nat Commun. 2014;5:5422.

57. Nakamura T, Watanabe A, Fujino T, et al. Apolipoprotein E4 (1-272) fragment is associated with mitochondrial proteins and affects mitochondrial function in neuronal cells. Mol Neurodegener. 2009:4:35.

58. Patel S, Cai X. Evolution of acidic $\mathrm{Ca}^{2+}$ stores and their resident $\mathrm{Ca}^{2+}$ permeable channels. Cell Calcium. 2015;57:222-30.

59. Patel $S$, Ramakrishnan $L$, Rahman $T$, et al. The endo-lysosomal system as an NAADP-sensitive acidic $\mathrm{Ca}(2+)$ store: role for the two-pore channels. Cell Calcium. 2011;50:157-67.

60. Melchionda M, Pittman JK, Mayor R, et al. Ca2+/H+exchange by acidic organelles regulates cell migration in vivo. J Cell Biol. 2016;212:803-13.

61. Zhang Y, Sloan SA, Clarke LE, et al. Purification and characterization of progenitor and mature human astrocytes reveals transcriptional and functional differences with mouse. Neuron. 2016;89:37-53.

62. Cruchaga C, Kauwe JSK, Nowotny P, et al. Cerebrospinal fluid APOE levels: an endophenotype for genetic studies for Alzheimer's disease. Hum Mol Genet. 2012;21:4558-71.

63. Cheng X-T, Xie Y-X, Zhou B, et al. Characterization of LAMP1-labeled nondegradative lysosomal and endocytic compartments in neurons. J Cell Biol. 2018;217:3127-39.

64. Lee AG. Lipid interactions with ion channels. Futur Lipidol. 2006;1:103-13.

65. Churamani D, Dickinson GD, Ziegler M, et al. Time sensing by NAADP receptors. Biochem J. 2006;397:313-20.

66. van Meer G, de Kroon AIPM. Lipid map of the mammalian cell. J Cell Sci. 2011;124:5-8.

67. Ruas M, Rietdorf $K$, Arredouani A, et al. Purified TPC isoforms form NAADP receptors with distinct roles for $\mathrm{Ca} 2+$ signaling and Endolysosomal trafficking. Curr Biol. 2010;20:703-9.

68. Galione A. A primer of NAADP-mediated Ca2+ signalling: from sea urchin eggs to mammalian cells. Cell Calcium. 2015;58:27-47.

69. Lu Y, Hao B, Graeff R, et al. NAADP/TPC2/Ca 2+ signaling inhibits autophagy. Commun Integr Biol. 2013;6:e27595.

70. Prasad H, Rao R. Amyloid clearance defect in ApoE4 astrocytes is reversed by epigenetic correction of endosomal pH. Proc Natl Acad Sci. 2018;115:E6640-9.

71. Pu J, Guardia CM, Keren-Kaplan T, et al. Mechanisms and functions of lysosome positioning. J Cell Sci. 2016;129:4329-39.

72. Ballabio A, Bonifacino JS. Lysosomes as dynamic regulators of cell and organismal homeostasis. Nat Rev Mol Cell Biol. 2020;21:101-18.

73. Thelen AM, Zoncu R. Emerging roles for the lysosome in lipid metabolism. Trends Cell Biol. 2017;27:833-50.

74. Sathyanarayan A, Mashek MT, Mashek DG. ATGL promotes autophagy/ Lipophagy via SIRT1 to control hepatic lipid droplet catabolism. Cell Rep. 2017;19:1-9.

75. Simonovitch S, Schmukler E, Bespalko A, et al. Impaired autophagy in APOE4 astrocytes. J Alzheimers Dis. 2016;51:915-27.

76. Lin YT, Seo J, Gao F, et al. APOE4 causes widespread molecular and cellular alterations associated with Alzheimer's disease phenotypes in human ipscderived brain cell types. Neuron. 2018:98:1141-1154.e7.

77. Nuriel T, Peng KY, Ashok A, et al. The endosomal-lysosomal pathway is dysregulated by APOE4 expression in vivo. Front Neurosci. 2017;11:1-12.

78. Bootman MD, Chehab T, Bultynck G, et al. The regulation of autophagy by calcium signals: do we have a consensus? Cell Calcium. 2018;70:32-46.

79. Pereira GJS, Hirata H, Fimia GM, et al. Nicotinic acid adenine dinucleotide phosphate (NAADP) regulates autophagy in cultured astrocytes. J Biol Chem. 2011;286:27875-81.

80. Singaravelu K, Lohr C, Deitmer JW. Regulation of store-operated calcium entry by calcium-independent phospholipase A2 in rat cerebellar astrocytes. J Neurosci. 2006;26:9579-92.

81. Kannan KB, Barlos D, Hauser CJ. Free cholesterol alters lipid raft structure and function regulating neutrophil $\mathrm{Ca} 2+$ entry and respiratory burst: correlations with Calcium Channel raft trafficking. J Immunol. 2007;178:5253-61.

82. Zhang B, Naik JS, Jernigan NL, et al. Reduced membrane cholesterol limits pulmonary endothelial Ca 2+ entry after chronic hypoxia. Am J Physiol Circ Physiol. 2017;312:H1176-84.
83. Itsuki K, Imai Y, Okamura Y, et al. Voltage-sensing phosphatase reveals temporal regulation of TRPC3/C6/C7 channels by membrane phosphoinositides. Channels. 2012;6:206-9.

84. Shiou $Y$-L, Lin H-T, Ke L-Y, et al. Very low-density lipoproteins of metabolic syndrome modulates STIM1, suppresses store-operated calcium entry, and deranges Myofilament proteins in atrial Myocytes. J Clin Med. 2019;8:881.

85. Shibasaki K, Ishizaki Y, Mandadi S. Astrocytes express functional TRPV2 ion channels. Biochem Biophys Res Commun. 2013:441:327-32.

86. Sun $Y$, Sukumaran $P$, Varma $A$, et al. Cholesterol-induced activation of TRPM7 regulates cell proliferation, migration, and viability of human prostate cells. Biochim Biophys Acta. 2014;1843:1839-50.

87. Peng KY, Pérez-González R, Alldred MJ, et al. Apolipoprotein E4 genotype compromises brain exosome production. Brain. 2019;142:163-75.

88. Boisvert MM, Erikson GA, Shokhirev MN, et al. The aging astrocyte Transcriptome from multiple regions of the mouse brain. Cell Rep. 2018:22:269-85.

89. Jones NS, Watson KQ, Rebeck GW. Metabolic disturbances of a high-fat diet are dependent on apoe genotype and sex. eNeuro. 2019;6:5 ENEURO.026719.2019

90. Finch CE, Shams S. Apolipoprotein E and sex Bias in cerebrovascular aging of men and mice. Trends Neurosci. 2016;39:625-37.

91. Hohman TJ, Dumitrescu L, Barnes LL, et al. Sex-specific Association of Apolipoprotein E with Cerebrospinal Fluid Levels of tau. JAMA Neurol. 2018; 75:989-98.

92. Kuo J, Hamid N, Bondar G, et al. Sex differences in hypothalamic astrocyte response to estradiol stimulation. Biol Sex Differ. 2010;1:7.

93. Shang Y, Mishra A, Wang T, et al. Evidence in support of chromosomal sex influencing plasma based metabolome vs APOE genotype influencing brain metabolome profile in humanized APOE male and female mice. PLoS One. 2020;15:e0225392

94. Shigetomi E, Patel S, Khakh BS. Probing the complexities of astrocyte calcium signaling. Trends Cell Biol. 2016;26:300-12.

95. Perkins M, Wolf AB, Chavira B, et al. Altered energy metabolism pathways in the posterior cingulate in Young adult Apolipoprotein e 4 carriers. J Alzheimers Dis. 2016;53:95-106

96. Filippini N, MacIntosh BJ, Hough MG, et al. Distinct patterns of brain activity in young carriers of the APOE- 4 allele. Proc Natl Acad Sci. 2009;106:7209-14.

97. Fernandez CG, Hamby ME, McReynolds ML, et al. The role of APOE4 in disrupting the homeostatic functions of Astrocytes and Microglia in aging and Alzheimer's Disease. Front Aging Neurosci. 2019;11:14. Epub ahead of print 11 February 2019. https://doi.org/10.3389/fnagi.2019.00014.

98. Zare-Shahabadi A, Masliah E, Johnson GW, et al. Autophagy in Alzheimer's disease. Rev Neurosci. 2015:26:385-95.

99. Anand S, Barnes JM, Young SA, et al. Discovery and confirmation of diagnostic serum lipid biomarkers for Alzheimer's disease using direct infusion mass spectrometry. J Alzheimers Dis. 2017;59:277-90.

100. Magi S, Castaldo P, Macrì ML, et al. Intracellular calcium Dysregulation: implications for Alzheimer's disease. Biomed Res Int. 2016;2016:1-14.

101. Kelly P, Hudry E, Hou SS, et al. In Vivo two photon imaging of Astrocytic structure and function in Alzheimer's disease. Front Aging Neurosci. 2018;10:219. Epub ahead of print 19 July 2018. https://doi.org/10.3389/fnagi.2018.00219.

102. Nuriel T, Angulo SL, Khan U, et al. Neuronal hyperactivity due to loss of inhibitory tone in APOE4 mice lacking Alzheimer's disease-like pathology. Nat Commun. 2017:8:1464.

103. Riddell DR, Zhou H, Atchison $\mathrm{K}$, et al. Impact of Apolipoprotein E (ApoE) polymorphism on brain ApoE levels. J Neurosci. 2008;28:11445-53.

104. Pascua-Maestro R, González E, Lillo C, et al. Extracellular vesicles secreted by astroglial cells transport apolipoprotein $D$ to neurons and mediate neuronal survival upon oxidative stress. Front Cell Neurosci. 2019;12:526. Epub ahead of print 10 January 2019. https://doi.org/10.3389/fncel.2018.00526.

105. Safieh M, Korczyn AD, Michaelson DM. ApoE4: an emerging therapeutic target for Alzheimer's disease. BMC Med. 2019;17:64.

106. Liao F, Hori Y, Hudry E, et al. Anti-ApoE antibody given after plaque onset decreases a accumulation and improves brain function in a mouse model of a amyloidosis. J Neurosci. 2014;34:7281-92.

\section{Publisher's Note}

Springer Nature remains neutral with regard to jurisdictional claims in published maps and institutional affiliations. 